\title{
A Problemática Cultural no Mundo Contemporâneo
}

Renato Ortiz'

\section{Resumo}

Diante da relevância contemporânea obtida pela cultura e seus derivados, mediante a combinação de história dos conceitos com etnografia das ideais, traça-se um amplo panorama das alterações semânticas da noção de cultura. Contudo, o propósito não é fazer um inventário exaustivo desse amplo quadro semântico. Ao tomar por suporte lógico duas categorias distintas, "constelação de sentido" e "camadas geológicas", analisadas em três fases que objetivam o entendimento da ideia de cultura: "culto, cultivado, arte", "cultura como totalidade" (nação e estudos antropológicos) e "cultura de massa". Porém, sem abrir mão da ruptura existente entre as três constelações, relativas à novidade que engendram na problemática da cultura, não são consideradas como se estivessem isoladas uma das outras. Opta-se por observar como elas estão mutuamente atravessadas; sobretudo, tornam-se referências recíprocas entre si.

Palavras-chave: Cultura. Constelação de sentido. Camadas geológicas. Mundo contemporâneo.

\section{Introdução}

Quando nos deparamos com um livro, outrora célebre, traduzido em vários idiomas, História Sociológica da Cultura, de Alfred Weber (1970), percebemos o quanto a temática cultural se transformou. Publicado em 1935 embora os argumentos principais tenham sido elaborados antes da guerra de 1914-1918 -, ele traça um quadro da história universal da humanidade: Egito, Babilônia, Grécia, Roma, Bizâncio, Idade Média, Barroco, Iluminismo, Mundo Ocidental. Todo esse esforço hercúleo, claramente eurocêntrico, termina com uma pergunta de caráter filosófico: em que ponto nos encontraríamos na corrente histórica dos acontecimentos. $\mathrm{O}$ autor quer diagnosticar os males do seu tempo, e descobre na predominância da técnica sobre o Espírito a razão das adversidades do presente. Dificilmente o leitor de hoje se contentaria

I Pesquisador do CNPq; Professor do Departamento de Sociologia da Universidade Estadual de Campinas (UNICAMP). 
com as explicações avançadas por Weber; entretanto, é justamente este exercício de alteridade que é esclarecedor. Ele revela um distanciamento que emerge o ato da leitura em um ambiente distinto da época na qual o texto foi elaborado. Minha intençáo é precisamente explorar os fundamentos que naturalizam nossa leitura atual, ou seja, compreender as mudanças que afetam a esfera da cultura no mundo contemporâneo.

Para isso, sou obrigado a tomar no passado alguns pontos de referência, visto que toda mudança se faz em relação a algo que lhe é anterior. Não é meu intuito encontrar uma definiçáo do conceito de cultura, pois esta é uma estratégia exaustiva e inútil, e foi tentada por dois antropólogos, Kroeber e Kluckhon (1952), quando encontraram 164 significados do termo em questão (passados tantos anos, o número teria obviamente aumentado). Parece-me mais produtivo tomar outro caminho. Mas, para isso, devo clarificar duas imagens que utilizarei para encaminhar minha reflexão: a de "constelação de sentido" e de "camadas geológicas".Por "constelação de sentido", entendo um conjunto formado por significados que giram em torno de uma mesma órbita e que delimitam um território específico. Não importa que esses significados sejam distintos (seria importante se tomássemos o caminho das definiçóes) e algumas vezes conflitivos entre si. O relevante é que eles podem ser agrupados no interior do mesmo conjunto. Consigo assim distinguir três constelaçóes: "culto, cultivado, arte", "cultura como totalidade" (nação e estudos antropológicos), "cultura de massa”.

Pode-se considerar que, até meados do século XX, cada uma dessas constelaçóes possuía certa autonomia, os significados, nos seus aspectos centrais, concentravam-se dentro de fronteiras relativamente seguras: os estudos antropológicos estavam distantes da esfera da arte; a noçáo de cultura de massa era a negação da grande arte e inaplicável às sociedades indígenas; a modernidade nacional era distinta da realidade etnológica considerada pela Antropologia clássica. No entanto, a partir de determinado momento essas fronteiras se rompem, a interação entre espaços relativamente estanques se intensifica e novos significados e redefiniçóes agregam-se ao quadro anterior. Esses significados, agora, sem girar na órbita das constelaçóes, depositam-se em camadas geológicas. E, enquanto fragmentos, elementos dispersos, são reinterpretados e integrados ao debate contemporâneo. Já a ideia de "camadas geológicas" nos permite escapar da noçáo de anacronismo como se o tempo tivesse sepultado 
as conotaçóes anteriores. Retiro um exemplo do debate sobre a pós-modernidade. A crítica às vanguardas, ao esgotamento do modernismo, à revalorizaçáo da tradição em contraposição à ideologia do progresso, à desconfiança em relaçáo ao universalismo, ao lugar do sujeito na criação do projeto artístico, ao interesse estético pelas tecnologias, particularmente multimídia. Tudo isso é uma temática recorrente na perspectiva pós-moderna; entretanto, a noção de criação, da arte como disposiçáo singular da subjetividade, de sua relativa autonomia, persiste. Por exemplo, a proposta de Charlie Jenks (1981) de uma arquitetura pós-moderna implica uma ruptura em relação ao passado, mas ela se afirma também como um novo projeto artístico. Quero esclarecerdizer com isso que essa noçãoproposta não pode prescindir da ideia de projeto artístico. Isso significa que, mesmo sem ocupar a mesma posição anterior, fragmentos da esfera da arte, deslocados do cânone tradicional, fazem agora parte das camadas geológicas às quais eu me referi.

\section{As constelações de sentido}

\section{Culto, cultivado, arte}

Uma das maneiras de se apreender a particularidade das sociedades europeias após a revolução industrial e as transformaçóes de ordem política é considerar o número de palavras inventadas ou ressignificadas na época: indústria, industrial, fábrica, classe média, socialismo, estrada de ferro, científico, proletariado, utilitário, estatística, greve. A lista poderia ser alongada, sem esquecer moderno, cuja conotação está associada à querela dos antigos e dos modernos, distancia-se dos séculos anteriores. O mesmo ocorre com "arte" e "cultura", que adquirem significados inteiramente novos, tornam-se representaçóes coletivas que denotam a emergência de uma sociedade em plena transformação. Arte referia-se a certo tipo de habilidade técnica, da medicina à carpintaria, tratava-se de um arte-sanato (articraft). Ao longo do século XVII o vínculo com a dimensão técnica começa a se romper, como observa Collingwood (1958), o sentido estético manifesta-se nas expressóes das "belas artes" (fine arts; beaux-arts; belle arti, shone kunst). Entretanto, é somente no XIX que o singular, escrito com maiúscula, substitui o plural "artes" e o qualificativo "belo" desaparece. Arte refere-se agora ao universo do "sublime" que não mais se confunde com a noção de beleza. Algo semelhante ocorre com cultura, e 
o termo deixa de se aplicar a um processo (cultivar os animais e a terra) para se transformar em um nome, em um objeto bem delineado (cultura de um povo; cultura superior; cultura popular) (WILLIAMS, 1983). Pode-se, assim, exprimir determinadas dimensóes da vida social. Elas são "apontadas", nomeadas por palavras que lhes dão consistência e veracidade. Consideremos o caso da literatura, retomando a interpretação proposta por Roland Barthes (1964). Ele considera que, durante o século XVI, ela se confundia com a questão da língua, ou seja, a emergência do francês. Nesse sentido, "ignorava a escrita", conformava-se à sua condição de texto meramente cifrado no idioma de um determinado país, a França; ela era, ainda, uma prática social de classe: resumia-se ao mundo dos letrados, o qual eradependente da aristocracia. Por volta de 1850, há uma conjunção de três fatores: mudanças demográficas na sociedade francesa, nascimento do capitalismo moderno, revoluçáo de 1848. Existem, portanto, três classes inimigas em disputa: aristocracia, burguesia, proletariado. Para quem deveria o escritor se dirigir? O "universal lhe escaparia" ao escolher qualquer um desses grupos em conflito. O dilema se resolve quando a literatura transforma-se em uma instituição, torna-se autônoma e a escrita adquire uma vida própria. $\mathrm{O}$ artista, neste caso o escritor, tem como única referência as fronteiras deste mundo no interior do qual partilha sua "superioridade" existencial com outros artistas. Mas sabemos que o advento da modernidade é também o momento da afirmação do indivíduo (da liberdade política à escolha de suas vestimentas, a moda): o artista, demiurgo do ato criativo, realiza sua subjetividade no seio deste universo estético, ele é o espelho no qual deve se mirar a vida. É esta ideia de separação, característica ao mundo da Arte, que lhe confere certa ambiguidade. Por um lado, ao se separar das outras atividades (religião, política, filosofia, interesses materiais), ela passa a ser vista como algo "elitista", sem "compromisso com a realidade", "exterior" à vida das pessoas. Por isso, os movimentos de vanguarda querem "reintroduzir a arte na vida" ou autores como Sartre (1948) cultivam a ideia de uma "literatura engajada" a serviço dos oprimidos. O que se encontrava fora de suas fronteiras, era rejeitado, deveria ser nela incluído. Entretanto, é também esta separação que possibilita a avaliaçáo inversa. Ao se retirar do mundo, a arte torna-se um território inatingível pela alienação material. Se o século XIX é o momento da consolidação da indústria, do trabalho e do comércio, atividades valorizadas pelo espírito burguês, ela seria o reverso disso tudo, 
contemplaria o lugar da crítica ao mundo fabril e à "mentalidade mesquinha" dos valores materialistas.

Não se deve imaginar que o termo cultura recubra inteiramente o campo da arte. Isso seria insensato. Mas gostaria de sublinhar algumas homologias que aproximam essas duas dimensóes. Consideremos a dicotomia kultur/zivilisation, cara aos pensadores alemães. Norbert Elias (1990) diz que civilização é um processo, movimento específico da realidade social e econômica, por exemplo, os avanços técnicos ou as realizaçóes do capitalismo moderno. Kultur restringe-se a produtos humanos, obras de arte, livros, sistemas religiosos e filosóficos. No entanto, essa diferenciação entre processo e produtos não é meramente descritiva, ela se fundamenta em uma escala de valores, a kultur é superior à zivilisation. Existiria, assim, uma oposição entre espírito e matéria. E, a cada um desses polos, pertenceriam atributos distintos: a kultur contrapóe-se ao utilitarismo, à fábrica, à produçáo, à técnica. Ela encerraria as virtudes espirituais de uma determinada sociedade. Trata-se do conjunto de valores morais, estéticos e filosóficos que preexistem à organização da vida social. É um ideal que nos orientaria na direção da "felicidade humana". Entretanto, para se atualizar, essa exigência de transcendência deve materializar-se em produtos - como lembrava Elias (1990). Quando Alfred Weber escreve seu livro são justamente eles, a afirmação de determinadas expressóes culturais, que são consideradas dignas da realização do Espírito: arquitetura, invençóes, filosofia. Por isso, ele pode narrar a história linear da progressão cultural que se faz desde os primórdios da vida em sociedade. O problema é que nem todos os "produtos" são equivalentes. Somente alguns podem ser agrupados em torno da ideia de "cultura superior", tradução do que haveria de melhor em cada sociedade. É preciso selecioná-los, “separar (novamente o mesmo verbo) o joio do trigo'. O artifício se faz ao agregar os objetos, as concepçóes e as filosofias de vida em torno da ideia de kultur. Tudo que lhe escapa automaticamente alinha-se ao lado da noção de zivilisation. Isso não se restringe à tradição intelectual alemá. Cultura, ao se associar à ideia romântica de um universo superior aos outros, homóloga ao mundo da arte, estabelece uma diferença fundamental entre "culto" e "inculto", "cultivado" e "ignorância". É isso que permite à Baudelaire considerar a fotografia uma paixão desprezível dos homens da multidão, incultos, incapazes de apreender as sutilezas da pintura. Eles se conformariam com a facilidade da reprodução técnica. Ou, de 
um autor como Matthew Arnold (1981), distinguir as inclinaçóes culturais e estéticas da aristocracia, da burguesia e do "populacho" 2 . Um exemplo: a música erudita. Em seu belíssimo livro A Grande Transformação no Gosto Musical, William Weber (2011) mostra como o conceito de música clássica emerge somente em meados do século XIX. O novo cânone é fruto de diversas transformações, ampliação do público dos concertos, convergência do gosto aristocrático com o da classe burguesa ascendente, o contexto político europeu, a vida urbana nas grandes metrópoles, Londres, Paris, Viena e Berlim; mas, sublinho, também um movimento de renovaçáo intelectual que ele denomina de "idealismo musical". Isto é, uma concepção romântica na qual a música clássica traduziria as verdadeiras inclinaçóes do "sublime", da autenticidade da "alma". Ela demarcaria, dessa forma, o território de um gosto "superior" antagônico à banalização da música tradicional e dos music-hall.

\section{Cultura como totalidade}

A problemática da nação emerge com a revoluçáo industrial e os dilemas das sociedades modernas. Gellner (1983) tem razão ao mencionar que a modernidade introduz uma ruptura em relaçáo às sociedades agrárias. Essas eram sociedades hierárquicas e segmentadas, na qual a classe dirigente representava uma pequena porcentagem da população e encontrava-se claramente separada dos habitantes de um mesmo território. Um exemplo: a escrita. Tratava-se de um conhecimento restrito a estratos específicos e de maneira nenhuma deveria ser generalizado entre "todos". Nas sociedades agrárias a circulaçáo de pessoas, objetos, vestimentas, era controlada por códigos e prescrições rígidas, assignando aos indivíduos o lugar que deveriam ocupar na escala social. A sociedade industrial rompe com essa ordem estratificada e segmentada (o que não significa que não possua uma hierarquia), incentivando a mobilidade e a circulação. Utilizando um termo do presente, eu diria, ela implica uma primeira desterritorialização das pessoas, uma vez que elas devem deixar o seu rincáo de origem para vender sua força de trabalho, como dizia Marx, ou seja, circular como mercadorias. Olhando desta perspectiva a nação surge como uma instância capaz de integrar as pessoas no seio de uma mesma totalidade. Se elas se encontram dispersas, é necessário um denominador comum que as

2 Remeto o leitor a um liuro clássico da tradição britânica, de Mathew Arnold (198I): Culture and Anarchy. 
aproxime, vinculando-as a um mesmo destino. A nação é uma consciência coletiva, um mecanismo que transcende o egoísmo individual, estabelecendo um vínculo social sólido entre os membros de sua população (RENAN, 1992). Os conflitos de classe, as desigualdades de origem, os interesses imediatos, devem ser suplantados em nome deste imperativo categórico. Por isso, é importante celebrar a memória nacional, o passado heroico, os grandes homens, a glória. Entretanto, o ritual de celebração deve se contentar com as exigências do presente, pois a memória é seletiva, esquece os infortúnios, as lembranças dolorosas. É vital, de alguma maneira, mascarar a realidade para se atingir um objetivo específico, a confraternização no seio de uma comunidade cultural. A memória nacional é distinta da memória histórica, ela vive do esquecimento e da seleçáo das lembranças. A cultura nacional surge, dessa maneira, como expressão das manifestaçóes de um povo, unidade orgânica que funda a solidariedade social. Cada nacionalidade seria uma entidade específica, constituiria um organismo (metáfora cara para Herder); nela se expressaria sua alma, sua identidade (HERDER, 1964). Este é o quadro no qual se insere o debate sobre a cultura popular. A canção, a poesia, as narrativas populares são percebidas como lugar no qual se depositam as raízes da tradição ancestral. Românticos e folcloristas irão valorizar esta tradição ameaçada pelas transformaçóes sociais. Ela representa um tesouro, uma riqueza, o solo da identidade nacional. Chamo a atenção para o contraste entre esta constelação de sentido e a anterior, na qual predominava a noção de separação. Neste caso, é a integraçáo, o vínculo entre os membros de uma sociedade que é valorizado. Contrariamente a uma cultura de elite, em contraposição ao popular, ou as virtudes imanentes à esfera da Arte, em dissonância com a mentalidade burguesa e industrial, a cultura nacional possui outra qualidade: ela aproxima o que a realidade distancia.

Iremos encontrar a mesma dimensão de totalidade nos estudos antropológicos. Embora a reflexão distancie-se da modernidade industrial, trata-se de compreender a vida dos "selvagens". Consideremos Tylor quem formula a primeira definição do conceito de cultura. Logo na abertura de "Primitive Culture", ele diz: "Culture or Civilization, taken in its wide etnographic sense, is that complex whole which includes knowledge, belief, art, morals, law, custom, an any other capabilities and habits acquired by man as a member of society" 
(TAYLOR, 2010, p. 1) ${ }^{3}$. Por que iniciar a frase com cultura e civilização? Há dois problemas. $\mathrm{O}$ primeiro diz respeito à perspectiva evolucionista predominante na época (o livro é publicado em 1871): existe uma ideologia do progresso que ordena as culturas e as civilizaçóes, ao longo de sua história elas passariam por etapas distanciando-se de sua condição original de "selvageria" (deixo de lado este aspecto). Em segundo lugar, constata-se que, as culturas desses povos são também civilizaçôes. Da mesma maneira que nas naçóes atuais (quando o autor escreve) existem códigos comuns, maneiras de se vestir, regras de matrimônio, valores morais e religiosos, as sociedades indígenas podem ser estudadas dentro da mesma perspectiva. Ou seja, a totalidade que abarca a naçáo é homóloga à das sociedades que não tinham ainda passado pelas transformaçóes do mundo moderno. Costumes, relaçóes de parentesco, rituais mágicos, técnicas de cultivo, enfim, as diversas práticas sociais, observadas isoladamente pelos antropólogos, podem ser agrupadas no interior de uma visão holística que as apreende. Essa perspectiva teórica irá se desenvolver, sobretudo, na tradição antropológica norte-americana ${ }^{4}$. A escola de Boas valoriza a ideia da cultura como uma totalidade. Ela transcenderia os indivíduos e seria uma realidade sui-generis (como dizia Durkheim em relação à sociedade). A ela corresponderia uma ciência específica capaz de decifrar os seus enigmas: a Antropologia Cultural.

\section{Cultura de massa}

A noçáo de cultura de massa surge no século XX e decorre das transformaçóes do capitalismo nas sociedades industriais. Já não nos encontramos no momento anterior quando o relevante era distinguir entre o moderno e o tradicional, o mundo fabril e o agrário. Importa qualificar as mudanças internas às sociedades que já se modernizaram. Não é casual que as primeiras discussóes em torno do tema se façam nos Estados Unidos, contrariamente à Europa, debate-se com a herança de duas grandes guerras e a ascensão do fascismo, a sociedade norte-americana vive um momento de prosperidade, um

3 Na versão em português do texto de Tylor, o trecho está traduzido nos seguintes termos: "Cultura ou civilização, tomada em seu mais amplo sentido etnográfico, é aquele todo complexo que inclui conhecimento, crença, arte, moral, leis, costumes, quaisquer outras capacidades e hábitos adquiridos pelo homem na condição de membro da sociedade" (CASTRO, 2005, p. 69, nota dos organizadores).

4 Consultar, entre outros: Alfred Kroeber, 1952. 
boom econômico que se espraia para a esfera cultural: publicidade, histórias em quadrinho, rádio, televisão, filmes de Hollywood etc. Uma nova configuração cultural se estabelece, a presença de bens simbólicos capazes de penetrar o gosto das diferentes classes e camadas sociais. Cultura de massa nomeia esta dimensão na qual o processo de produção e difusão cultural transformou-se radicalmente. Ou como a considera Edward Shils (1959), ela é a expressão de uma sociedade na qual a massa da população foi incorporada ao seu centro. Isso significa que os níveis de cultura, antes estanques, restritos às diferenças de classe, com o consumo generalizado, estariam diminuindo. Trata-se, portanto, de uma "nova ordem social". Não é difícil perceber as mudanças em curso. Sobretudo, elas incidem na forma como a esfera da cultura passa a ser percebida. O conceito possuía um antepassado ilustre, multidão, termo que cairá em desuso. Multidão é uma típica expressão da modernidade industrial, designa uma dimensão da vida social em contraposição ao indivíduo, outro emblema do XIX 5 . Enquanto o indivíduo encarna as virtudes políticas e morais, capacidade de escolha, realização pessoal, a multidão é a sua contra cara, o seu lado negativo. Ela seria um agregado amorfo de pessoas, um todo homogêneo no seio do qual cada um perderia sua individualidade. O homem na multidão, como no conto de Edgar Alan Poe, é absorvido por sua força irracional, ela sufoca sua integridade, a idiossincrasia que o define com alguém capaz de uma açáo racional. Por isso, ele necessitaria de um líder espiritual ou político, ao se comportar como um "rebanho", sem vontade própria, não mais conseguiria falar por si mesmo. Do ponto de vista conservador, a multidão referia-se ainda à "plebe", ao "populacho", enfim, aos que não possuiriam os atributos inerentes ao homem cultivado. Cultura de massa afasta-se da perspectiva negativa anterior. Ela se torna afirmativa, corresponde à forma da organização dos bens culturais nas sociedades modernas. É importante sublinhar este aspecto. Nenhuma sociedade anterior havia trabalhado a esfera cultural desta forma, ou seja, de maneira ampla e em estreita relação com a expansão econômica. A produçáo e a distribuição em massa dos bens culturais implicava uma reorganização da cadeia produtiva e da relação entre os produtos e o consumidor (daí a importância da publicidade, não como maneira de "anunciar" as coisas,

5 O tema da multidão atravessa a obra de diversos autores, por exemplo, Durkheim e Gabriel Tarde, mas a obra "exemplar" que condensa os argumentos principais a seu respeito é certamente a de Gustave Le Bon (1980). 
dizia-se antes, anúncios, mas como elemento integrado ao marketing e à produção). Gostaria de sublinhar nesta constelação de sentido duas dimensóes. A primeira diz respeito à técnica. Não há cultura de massa sem os meios técnicos que a possibilitem se efetivar. Esses são os "meios de comunicação de massa”: jornais, revistas, cinemas, outdoors, rádio, televisão. Eles constituem os veículos preferenciais de um novo tipo de expressáo simbólica. Devido à sua natureza, são capazes de distribuir os bens culturais a distância, atingir um espaço até então restrito a fronteiras bem determinadas. Uma sociedade e uma cultura de massas somente podem existir através dos meios de comunicação. Eles surgem como instituições de socialização das pessoas, fazem concorrência à escola, família e religião. A "nova modernidade" ancora-se nas conquistas técnicas; por isso, a televisão transforma-se em um ícone, o emblema de toda uma época. Nesse sentido, McLuhan (1965) dirá que "o meio é a mensagem", ou seja, o elemento técnico, e náo propriamente o conteúdo por ele veiculado, seria o aspecto nodal na orientaçáo do comportamento humano. $\mathrm{O}$ segundo aspecto vincula-se ao mercado. Pode-se afirmar que escritores como Flaubert lutavam contra o folhetim, forma literária utilizada para se vender jornais; que os pintores consideravam a fotografia um artifício técnico voltado unicamente para os interesses pecuniários (em Paris, na Exposição Universal de 1855, a fotografia é excluída do saláo das artes tendo de se conformar, no Palácio das Indústrias, com seu status de objeto industrial e comercial). Mas, durante o século XIX, as exigências do "mercado" (como dizemos atualmente) não exerciam uma hegemonia irrestrita sobre a esfera cultural. É justamente neste período que a Arte conquista sua autonomia. Nas constelaçóes "culto cultivado, arte" e "cultura como totalidade", a temática mercadológica inexiste ou é secundária, conjuntural. A construção da nação faz-se em torno da questáo identitária e os estudos antropológicos passam ao largo deste tipo de consideração. Entretanto, com o advento da sociedade de massa as coisas se invertem, como bem percebeu Adorno, a arte cada vez mais integra na sua concepçáo estética elementos específicos da "lógica capitalista". É sintomático que, pela primeira vez, a crítica marxista analise a esfera da cultura a partir da categoria mercadoria, antes restrita ao nível econômico. Adorno e Horkheimer no texto "O iluminismo como mistificação das massas" percebem como a lógica mercantil insere-se na configuração das formas culturais que se delineiam. A cultura de massa, devido a uma exigência da produção e da difusão ampliada, 
deve ser padronizada e consumida por "todos". Daí importância da ideia de homogeneização, busca-se sempre um termo médio capaz de unificar os gostos, padronizá-los dentro de uma "massa" uniforme.

\section{As transformações}

Ao longo do século XX, um conjunto de mudanças incide na esfera cultural, algumas são recentes outras potencializam elementos esboçados em algumas das constelaçóes de sentido apresentadas anteriormente. Um aspecto refere-se ao lugar da técnica no mundo contemporâneo. Em qualquer sociedade as invenções e os procedimentos técnicos implicam possibilidades de realizaçóes materiais e sociais: os canhóes e as velas foram decisivos para a conquista dos mares e a expansáo europeia; o aprimoramento do mecanismo do relógio foi essencial para a mensuração nas experiências científicas; o surgimento da máquina de costura reformulou a indústria textil ${ }^{6}$. Entretanto, não é a simples relação causal entre técnicas específicas e a concretização de determinados objetivos que deve ser levada em consideração. Os historiadores estabelecem, ainda, um vínculo entre os sistemas técnicos e a forma de organização das sociedades. É isso que permite um autor como Lewis Munford (1987), utilizando um critério tecnológico, distinguir entre diferentes fases históricas: eotécnica (anterior à revolução industrial), que seria marcada pela utilização de um complexo de água e madeira; paleotécnica (correspondente ao advento da indústria moderna), um complexo de carvão e ferro; neotécnica, um complexo de eletricidade e ligas metálicas. Não é tanto a periodização proposta que gostaria de reter (ela é insuficiente), mas o vínculo existente entre determinado momento histórico (Munford considera uma civilização) e o desenvolvimento tecnológico. Ou seja, cada "época" conteria em si a base material capaz de assegurar sua própria reprodução. Nesse sentido, a invenção da máquina a vapor não pode ser dissociada de um padráo social mais amplo no qual o trabalho industrial torna-se o centro de um novo tipo de organização social. Mas isso significa também que, ao longo do século XIX, teriam ocorrido duas "revoluçóes industriais", a primeira, clássica, inicia-se na Inglaterra por volta de 1780; a segunda, um século depois na qual as fontes de energia são o petróleo e a eletricidade. Um sistema técnico é um conjunto no qual se

6 Ver, por exemplo: Carlo Cipolla, 1989; David Landes, 1983. 
integram técnicas diversas; porém, a partir de certo ponto de equilíbrio, ele não consegue mais se expandir, porque os limites tecnológicos bloqueiam seu desenvolvimento como um todo ${ }^{7}$. A modernidade de "Paris capital do século XIX" que encantava Walter Benjamin associa-se, sobretudo, à segunda revolução industrial: a "fada eletricidade" que movimenta os bondes, o surgimento do automóvel e do cinema, o encurtamento das distâncias com a expansão da rede ferroviária. A base material na qual se apoia e se constrói essa modernidade tem implicaçóes na vida social e cultural: surgimento das lojas de departamento, anonimato da vida na grande metrópole, presença da multidáo que possibilita e entrava os passos do flâneur, as novas disposiçóes estéticas que captam o movimento (impressionismo), a sensibilidade individual diante da aceleração do tempo (viagens de trem) etc. $\mathrm{O}$ ritmo dessas mudanças irá se acelerar ao longo do século XX, observando-se a emergência de um sistema técnico que integra e suplanta o anterior. Quando Daniel Bell (1973) publica seu livro sobre a sociedade pós-industrial, um dos elementos chaves para compreendê-la diz respeito às mudanças tecnológicas. Elas incidem na esfera econômica, produçáo maior de bens com a diminuiçáa dos custos; social, surgimento de uma "nova classe" na qual o conhecimento técnico-científico torna-se crucial; consolidaçáo de um padrão de racionalidade e de funcionalidade cujas implicações atingem inclusive a esfera educacional; "revolução" no mundo dos transportes e da comunicação. Durante as décadas de 1980 e 1990 (quando se discute sobre a pós-modernidade e a globalizaçáo) este movimento se acentua, definindo as características do que se convencionou chamar de "sociedade informacional", "sociedade em rede", "sociedade de conhecimento" etc. ${ }^{8}$. A organização da vida em sociedade assenta-se na materialidade das "novas tecnologias": invenção do transistor, microprocessadores, advento dos computadores e da microeletrônica, avanços obtidos na transmissáo de informaçóes via fibras ópticas, internet. Por isso, tornou-se corriqueiro no debate atual a contraposição entre dois momentos históricos distintos. Uma maneira de captá-los é através da metáfora que indica a passagem do fordismo para o capitalismo flexível. Enquanto no fordismo a organização do trabalho e o sistema produtivo eram rígidos, monolíticos, repetitivos, o novo padrão

7 Utilizo a ideia de sistema técnico de Bertrand Gille (1978).

8 Entre tantos liuros, cito um, talvez bastante esquecido de Adam Schaft (1991): A Sociedade Informática. 
seria flexível, diversificado, descentralizado ${ }^{9}$. Neste esforço comparativo que explicita o contraponto entre duas épocas, a técnica - como dimensão real do processo de produçáo ou figura metafórica que denota uma tendência em curso - é determinante. Ela condensa social e simbolicamente as virtudes e o potencial de outra contemporaneidade.

Isso terá consequências junto à esfera cultural. $\mathrm{O}$ advento do computador, ao propiciar a redução da informação a uma unidade informacional, permitiu uma circulação de textos, imagens e sons até então desconhecida. Uma série de práticas sociais pode, dessa forma, associar-se aos aparatos tecnológicos. Um exemplo: o hipertexto. Muitas vezes nos referimos à "revolução de Gutemberg" (a substituição do livro copiado à mão pelo impresso) uma importância que nos faz esquecer que muito do seu formato anterior é preservado: codex, distribuição do texto na superfície da página, numeraçáo, índices e sumários. O hipertexto é fundamentalmente distinto da impressão em papel. Ele resulta da composiçáo, na tela do computador, tablet ou telefone celular, de uma superposição de texto, imagem e som. Ele não é um objeto singular como o livro, está interconectado a outros hipertextos, e sua utilização é potencializada pelas interligaçóes que o constituem. $\mathrm{O}$ ato da leitura toma, assim, outra configuraçáo. Pode-se dizer o mesmo da escuta musical. Ela já náo se apoia apenas em objetos materiais específicos, disco ou CD, tampouco em programas pré-fixados transmitidos pelo rádio, com a generalizaçáo da internet o ouvinte tem a possibilidade constituir o elenco de suas músicas "prediletas", isto é, fatiar a oferta disponível no mundo digital e organizá-la para o seu uso pessoal. A prática da utilização dos bens culturais transforma-se conferindo às pessoas uma capacidade de ação (ela não é irrestrita) sobre os bens simbólicos. Não se pode esquecer que o mundo contemporâneo é, em vários sentidos (não necessariamente todos), mediado pela técnica. Certamente, isso é um traço que deriva da modernidade industrial; entretanto, ele irá se acentuar ao longo dos anos. Escutar música, olhar as imagens, ler, são atos rotineiros realizados em um tablet ou em um telefone celular; enviar mensagens, comunicar-se, marcar encontros, ver e tirar fotos, filmar um evento são açóes que manipulam mecanismos técnicos inseridos em nossa rotina. Tais açóes tornam-se

9 Vários autores escreveram dentro desta perspectiva. Cito alguns: S. Lash e J. Urry (1987) - The End of Organized Capitalism; David Harvey (1990) - The Condition of Postmodernity. 
banais, fazem parte de um ambiente mobiliado pela tecnologia. Dentro desse contexto, fragiliza-se a separação entre técnica e cultura pressuposta na constelação "Culto, cultivado, arte". A afirmação, "a pintura é arte, a fotografia é técnica”, tornou-se insatisfatória. Em um mundo, no qual a imagem é reproduzida e modelada digitalmente, a experiência visual não se limita aos ideais artísticos do século XIX. Nesse sentido, a hierarquia estabelecida entre kultur e zivilisation se esvai. O Espírito não é superior à matéria. Pode-se interpretar a aproximação desses polos contraditórios de pontos de vista distintos: a) a técnica, ao invadir o universo espiritual, desumaniza o homem; b) a aproximação entre esses mundos é possível pela humanização da técnica. Não me interessa discutir tais posições teóricas (Simondon tem razão ao afirmar que a oposição entre cultura e técnica é uma ilusão). Sublinho, porém, a nitidez das fronteiras estabelecidas se desfaz. Dificilmente as realizaçôes técnicas incrustradas nas práticas cotidianas poderiam ser vistas de maneira negativa, espécie de alienação cultural. Para isso, seria necessário novamente separá-las da realidade, considerá-las como objetos autônomos distantes da vida social. Entretanto, devido à própria amplitude que os objetos tecnológicos adquirem, eles tornam-se agora uma referência positiva: conquistas, capacidades que valoram, inclusive, as relaçóes sociais. Consideremos, por exemplo, o livro A Era do Acesso de Jeremy Rifkin (2001), best-seller do senso comum planetário. Para ele, o mundo contemporâneo teria eliminado as bases da vida moderna. $\mathrm{O}$ mercado estaria dando lugar às redes, e a noção de propriedade estaria sendo rapidamente substituída pelo acesso. O que importa é a interação entre o servidor e o cliente, pois interessa ao consumidor unicamente conectar-se (e não possuir) àquilo que se busca. $\mathrm{O}$ mundo se dividiria entre os que possuem ou náo acesso. E, no interior dos portais, a riqueza seria o equivalente à quantidade de informaçóes (oportunidades) disponíveis. Deixo de lado o cerne dessa tese insensata, porque o que salta aos olhos é como a tecnologia é vista de maneira superlativa, fantasmagórica, como diria Benjamim. Tudo se passa como se ela fosse o demiurgo, o centro irradiador das relaçóes econômicas, sociais e culturais. Essa não é uma perspectiva restrita a um autor, visto que corresponde a uma atitude mais ampla, na qual uma visáo idílica e acrítica prevalece (curioso, o termo revolução, aplicado, sobretudo, ao domínio da política, migra para a esfera tecnológica, onde as "revoluçóes" ocorrem a cada aperfeiçoamento técnico). Imagina-se que os problemas políticos possam ser 
resolvidos no ciberespaço: as desigualdades e os conflitos sociais com a inclusão digital; os problemas educacionais com a Pedagogia a distância. Cada manifestação técnica eliminaria os inconvenientes e as contradiçóes manifestas na sociedade. Diante do progresso tecnológico, a dimensão negativa anterior, herança do XIX, transmuta-se em positividade inquestionável.

Eu havia chamado a atenção para a importância dos meios de comunicação na constelação "cultura de massa", pois propiciavam os canais de distribuiçáo dos bens culturais em escala ampliada. As mudanças recentes radicalizam este processo: satélites, cabos óticos submarinos, computadores, tablets, telefones celulares, televisão a cabo, internet, uma série de inovaçóes permitem uma comunicação cada vez mais rápida entre grupos e indivíduos. A globalização tecnológica e a mundialização da cultura acrescentam ao quadro anterior a dimensão transnacional; inúmeros aplicativos - Skype, Facebook, Twiter asseguram a interaçáo dos indivíduos independentemente do lugar onde estão. Entretanto, já não mais nos encontramos diante de meios de comunicação de massa. Há algo de incongruente nesse tipo de conceituação. Se a noção de massa havia substituído a de multidão nos anos 1940 com a emergência de um novo sistema técnico, o que era homogêneo se decompóe. A ideia de cultura de massa estava em consonância com um momento no qual as indústrias culturais funcionavam como centro de produção de bens simbólicos, distribuindo-os em seguida através dos canais tecnológicos disponíveis; rádio, jornais, televisão, cinema. Essas formas de comunicação não desaparecem, fazem parte de nosso cotidiano; mas, ao lado de outras, são redefinidas dentro de um contexto, diriam os economistas, "flexível". Não se deve imaginar que a existência dos bens culturais de massa tenha sido no passado sinônimo de fordismo. Esse tipo de perspectiva, sugerida por diversos autores, no fundo, simplifica as coisas. O modo de produçáo de Hollywood nunca foi fordista, ele pressupunha uma concentração de estúdios em Los Angeles; porém, a maneira como os filmes eram elaborados nada tinha de uma linha de montagem semelhante à indústria automobilística. Tampouco a fabricação industrial da telenovela no Brasil pode ser assimilada ao taylorismo da organização de trabalho (existe o autor do texto, os diversos diretores, a interpretaçáo dos atores, atrizes etc.) (STEIGER et al., 1985). Na esfera cultural os modelos utilizados na esfera produtiva são pouco consistentes, porque o trabalho intelectual é de natureza distinta e não equivale ao tipo de trabalho "em migalhas" que 
é realizado nas fábricas (utilizo um termo de George Friedmann). Nesse sentido, não nos encontramos diante de uma produçáo indiferenciada na qual os atores envolvidos são anônimos e intercambiáveis entre si, pelo contrário, o cinema e a televisão cultivam os ídolos, as celebridades. O star-system, como dizia Morin em L'Esprit du Temps, é habitado por semideuses. As virtudes de cada um são idiossincráticas, intransferíveis. Massa refere-se, portanto, a um tipo de "cultura média", elaborada e distribuída pelas indústrias culturais. Ela é homogênea, mas não propriamente fordista. Não é casual que o ícone televisão tenha cedido lugar à internet. A televisão resumia de maneira metafórica uma época na qual a comunicação fazia-se através de uma via de mão única, o espectador assistia a uma programação prefixada pelas agências televisivas. $\mathrm{O}$ funcionamento da internet repousa na capacidade de interligar pessoas e grupos, eles se encontram em "rede". A massa ancora-se na existência de um todo indiferenciado, ela é única, coesa; rede nos remete à ideia de interligação, cada lugar é um ponto singular conectado a um conjunto de outros pontos. A comunicaçáo se dá quando eles são acionados e interagem entre si. Ela não possui um centro, nada tem de homogênea. É sua discontinuidade (o que diferente é de heterogeneidade) que possibilita a sua existência. $\mathrm{O}$ enfraquecimento da noçáo de cultura de massa torna-se claro quando se toma o mundo como cenário. A CNN é um canal de alcance mundial, mas não é de massa (não faz sentido falarmos em "massa planetária"). Ela tem o seu centro fixado nos Estados Unidos, pretende, inclusive, tornar hegemônica um tipo de visão mundo, porém, atua em um espaço no qual existem diversos concorrentes, $\mathrm{Al}$ Jazira, TV5 Monde, Deutche Welle, BBC etc. O mundo atual encontra-se, certamente, conectado tecnologicamente; mas, ele não é social e culturalmente integrado, não constitui uma "sociedade global", um todo homogêneo abarcando uma mesma realidade planetária.Outra dimensão das mudanças contempla a esfera econômica. Um aspecto refere-se à discussão que vínhamos considerando anteriormente. Diferentemente dos anos 1930 e 1940, sobretudo nos Estados Unidos, quando o tema da sociedade de massa predomina, temos hoje uma visáo de segmentaçáo do mercado. Por isso, a metáfora da passagem do fordismo ao capitalismo flexível torna-se crível. Ela circunscreve uma época na qual a produção de massa é superada por outra. A lógica anterior fundamentava-se na existência de um público homogêneo interessado em consumir produtos materiais e culturais padronizados. Qualquer manual de marketing atual ensina justamente o contrário: os produtos devem ser 
direcionados a segmentos específicos e não à totalidade dos consumidores. Isso ocorre a nível nacional, diferencia-se entre um público juvenil, feminino, masculino, étnico, de classes (segundo os critérios mercadológicos: A, B, C), e também transnacional. $\mathrm{O}$ mercado global não é de massa embora sua dimensão ultrapasse em muito as fronteiras nacionais. Interessa vender produtos em escala global, mas náo necessariamente para todas as pessoas do planeta, o público consumidor de McDonald's não é o mesmo das bolsas Gucci. Pode-se inclusive citardizer, utilizando uma categoria de Bourdieu, que o processo de distinção social se faz no interior desse mercado segmentado. Degustar um Nespresso (a publicidade com George Clooney garante) é distinto de vestir-se com roupas "made in China". As diferenciaçôes de classe, de identidade, de "bom" ou "mau gosto", realizam-se através de bens materiais e simbólicos que nos distanciam da ideia de massa. A própria noção de "sociedade de consumo", surge no final da década de 1960 início de 1970, enfatizando esta dimensão heterogênea. Como pondera Baudrillard (1970) em seu livro precursor, La société de consommation, o consumo náo se esgota simplesmente no ato da compra ou da consumação de determinado bem. Uma "sociedade de consumo" possui uma especificidade quando a utilidade dos objetos deixa de ser central na sua aquisição pelo consumidor. A dimensão funcional (um carro serve para locomover-se; uma máquina de lavar roupas, para lavar roupas) encontra-se enredada em uma floresta de símbolos vinculando cada um deles a um imaginário simbólico explorado pelas técnicas de propaganda e marketing. Ao escolher um objeto o indivíduo faz parte desse universo que o transcende, cujos ícones se materializam na dimensáo funcional que caracterizam os símbolos. É essa dimensão simbólica "agregada” que caracteriza uma sociedade de consumo. Ela a diferencia de um tipo de produção que se esgotaria na dimensão material e utilitária dos objetos. Nesse sentido, o consumidor insere a idiossincrasia do seu mínimo. Eu nas escolhas que faz, isto o afasta da premissa anterior na qual os produtos padronizados eram concebidos para contentar a todos, isto é, um indivíduo médio. As técnicas de venda e de marketing irão, inclusive, integrar essa dimensão psicológica ao traçar o seu "perfil". Ou seja, uma identidade de consumo pode ser agrupada em torno de algo coletivo. Ao traçar os perfis dos consumidores a intenção é atingir grupos diferenciados, e não a massa, que partilham em comum gostos, afinidades, estilos de vida (por isso, os dados pessoais veiculados no Facebook, Twiter, sites 
de compra etc. tornaram-se informaçóes valiosas para a elaboração de perfis a serem explorados pelas empresas). A emergência do marketing transcultural e o interesse cada vez maior que os executivos das grandes empresas têm pelos aspectos culturais, envolvendo a venda de seus produtos, faz com que a ideia de massa ceda lugar à de diversidade. Assim, o mercado global é explorado na sua transnacionalidade; mas, sua dimensão planetária incorpora as diferenças existentes entre países, culturas, grupos étnicos, classes sociais, gênero etc.

Outro aspecto diz respeito à presença dos interesses mercadológicos na esfera cultural. Se por um lado o tema da massa tende a se debilitar, a questão do mercado possui um destino distinto. Torna-se cada vez mais um desafio incontornável. Pode-se considerar que, no âmbito da constelação anterior, o debate cultural girava em torno da problemática da indústria cultural. Os dois termos, indústria e cultura, à primeira vista incompatíveis entre si (vistos, é claro, a partir do horizonte culto), procuravam dar conta da dimensão mercadológica que agora perpassava o universo cultural. É nesse sentido que Adorno (autor do conceito em parceria com Horkheimer) dirá que “[...] as mercadorias culturais da indústria se orientam segundo o princípio de sua comercialização e não segundo seu próprio conteúdo e sua figuração adequada” (ADORNO, 1975, p. 288). A ideia da existência de indústrias de cultura combina uma metáfora do século XIX (o advento da revoluçáo industrial) com a emergência dos meios de comunicação de massa. A noção de racionalização do trabalho, previsibilidade da produção, específica ao domínio econômico, desloca-se para o entendimento dos bens culturais. Entretanto, percebe-se que, ao longo do século XX, a metáfora indústria perde em força e poder de convencimento, inclusive quando considerada sua dimensão puramente econômica (flexibilização do trabalho e da produçáa). Isso não significa que a questáo do mercado torna-se secundária; pelo contrário, ela se reforça, embora venha a adquirir outra configuração. Os bens culturais atuais não mais necessitam ser produzidos por "indústrias". Este é um aspecto secundário do debate contemporâneo, mas, dificilmente escapam às imposiçóes das trocas comerciais. Um exemplo: a transformaçáo da alta costura em prêt à porter. Percebe-se que antes os vestidos eram únicos, feitos sob medida. Inventa-se, agora, um padrão para ser replicado em maior número. Entretanto, não se pode comparar a moda de luxo às condiçóes da produção televisiva. $\mathrm{O}$ padrão 
é individualizado pela griffe do costureiro, e não significa padronização no sentido de se fabricar em série um determinado produto. As marcas de luxo são apreciadas por que são rarefeitas, diferenciam-se do que seria um consumo de fácil aquisição. Mas a própria noção de consumo, que se ampara na subjetividade de um sujeito ativo (ele possui a capacidade de escolha), irá expandir a dimensão de mercado para uma esfera que náo se encontrava contemplada na ideia de indústria. É o caso do turismo. Não me refiro apenas à organização da viagem (compra de passagem, estadia em hotéis, deslocamento etc.). Mas, como observa John Urry, os lugares, as paisagens sáo também consumidas. Para esse autor:

"Places are chosen to be gazed upon because there is an anticipation especially through day-dreaming and fatansy, of intense pleasures, either on a different senses from those customarily encountered. Such anticipation is constructed and sustained through a variety of non-tourist practices, such as films, newspapers, TV, magazines, records and videos which construct that gaze. Such practices provide the signs in terms in which the holiday experiences are understood, so that what is seen is interpreted in terms of these pre-given categories". (URRY, 1995, p. 132) ${ }^{10}$.

O indivíduo aparece, dessa forma, enredado em um emaranhado, no qual a dimensão mercadológica é inseparável de suas próprias práticas. Com o desenvolvimento da globalização, isso irá se expandir ainda mais. Basta olharmos as grandes corporaçóes transnacionais que se ocupam da música, dos livros e da internet, porque influenciam diretamente os hábitos de ouvir música, de leitura, ou de "viajar" no mudo digital. O caso do negócio da música é interessante (NICOLAU, 2014). Os dados demonstram que o consumo de CDs e discos, ou seja, da música gravada, tem diminuído consideravelmente. Isso não significa que as corporaçóes estejam à beira da falência, significa apenas que novos atores são agora incorporados ao circuito de veiculaçáo e consumo da música: as indústrias de tecnologia e de telecomunicação. A internet está longe de ser um espaço neutro no interior do qual as pessoas escolhem

10 "Escolhem-se lugares para serem vistos porque há uma antecipação, especialmente pelo sonhar acordado e pela fantasia, de prazeres intensos, ou sentidos diversos daqueles encontrados costumeiramente. Tal antecipação é construída e sustentada por uma variedade de práticas não turísticas, tais como filmes, jornais, TV, revistas, gravações e videos que constroem o olhar. Essas fornecem os signos em termos dos quais as experiências do feriado serão compreendidas. De maneira que o que é visto é interpretado segundo essas categorias" (Nota dos organizadores). 
livremente as opções que lhes pareçam as melhores. Essa visão idílica é contradita por uma série de estratégias utilizadas pelas agências de entretenimento. A prática da "monetarização" evidencia isso claramente. O termo é sugestivo. Ele não está vinculado a uma determinada venda, pois o consumidor não tem nenhum gasto pecuniário ao ouvir determinada canção. A música em si deixa de ser um objeto de venda. Entretanto, Google é capaz de organizar os usuários em listas de consumidores potenciais, ordenando-os em categorias segundo os seus perfis. Sáo essas informaçóes que adquirem no mercado (não apenas musical) um interesse estratégico de marketing.

Não seria a cultura uma mercadoria? A frase é composta pelo sujeito (cultura) e o predicado (mercadoria). Deixo de lado o primeiro aspecto, o uso do singular, cultura, para centrar-me sobre o segundo. A afirmação tornou-se uma espécie de senso comum. Vamos encontrá-la tanto nos críticos da situação atual quanto nos empresários que prezam justamente o aspecto comercial. Porém, do ponto de vista conceitual, dificilmente poderíamos reduzir os universos simbólicos à noçáo de mercadoria. Retomo Marx para ilustrar meu argumento. Ele faz uma distinção entre valor de uso e valor de troca. O uso vincula cada objeto à sua utilidade. Isso significa que ele se encontra inscrito no corpo desses elementos, aquilo que ele é (ferro, queijo, diamante etc. - são exemplos do autor). Dito de outra maneira, o valor de uso náo existe fora dos objetos (eles mesmos). O valor de troca é uma relação quantitativa, uma proporçáo na qual os diferentes valores de uso podem ser trocados entre si (1 quarter de queijo = a kg de ferro). As trocas náo se restringem, porém, a algumas mercadorias. Elas constituem um sistema, possuem uma lógica que pode ser generalizada a tudo o que ele abarca. $\mathrm{O}$ quadro geral das trocas pode ser entáo resumido: $\mathrm{z}$ mercadoria $\mathrm{A}=\mathrm{u}$ mercadoria $\mathrm{B}$ ou $=\mathrm{v}$ mercadoria $\mathrm{C}$ ou $=\mathrm{x}$ mercadoria $\mathrm{E}$ ou etc. Trata-se de uma cadeia de trocas quantificada em torno de algo comum. $\mathrm{O}$ valor de troca implica a ideia de um "equivalente universal", denominador comum de toda e qualquer troca (Marx irá associá-lo em sua análise ao capital). As mercadorias são trocadas por que podem ser reduzidas a este denominador. Ele é a mediação quantificada entre objetos díspares, o fetiche que envolveria as relaçóes sociais no universo capitalista. Pergunta: existiria um equivalente universal na esfera dos bens simbólicos? A resposta é não. O mundo do simbólico é o domínio da diferença. Consideremos a língua. Ela é constituída de oposições. Saussure (2002) nos ensina 
que a palavra mãe não existe em si, “só”, um dado imediato. Ela se encontra articulada a outras: pai, filho, irmá etc.; por isso, esse autorafirmadiz que o "sentido das palavras é uma coisa essencialmente negativa", entendendo por negativo as oposiçóes que situam cada uma delas em um jogo de interaçóes - por exemplo: o termo suplício adquire sentido quando contraposto a martírio, tortura, aflição, agonia etc. Podemos considerar outros exemplos. Todo debate sobre as identidades implica a delimitação de um território específico e sua contraposição ao que é visto como externo. A identidade possui uma face positiva (aquilo que ela "é”) e outra negativa (o que não "e’"). Ser brasileiro significa diferenciar-se dos outros: americanos, franceses, japoneses etc. As identidades não são intercambiáveis, não podem ser trocadas umas pelas outras da mesma forma que as mercadorias. Por isso, um autor como Bourdieu, ao falar em "mercado linguístico", procura por regras específicas das trocas linguísticas (BOURDIEU, 1982). O valor do discurso depende da competência dos locutores e da forma como eles se apropriam de um determinado idioma. Todos os falantes de uma mesma comunidade são capazes de falar esta língua. Todavia, como ocupam posiçóes hierárquicas desiguais no espaço social, a autoridade da fala de cada um deles não é idêntica. A fala autorizada está articulada à posição dos indivíduos no campo dos falantes, o que possibilita que alguns enunciados sejam mais legítimos do que outros. $\mathrm{O}$ mercado de bens linguísticos diferencia-se em função da distribuição desigual da maneira de se apropriar dos idiomas. Ou seja, apesar de o autor utilizar a metáfora mercado para desenvolver o seu raciocínio, ele funciona segundo regras simbólicas que não podem ser reduzidas a intençóes puramente mercantis. Presença do mercado, impossibilidade dos bens simbólicos serem tratados como mercadorias. Como combinar essas dimensóes aparentemente antagônicas? Creio que é possível dizer que o espaço das trocas simbólicas existe sempre em contexto; por isso, ele é atravessado pelos elementos de caráter mercadológico. Se os bens culturais escapam ao destino de serem mercadorias (no sentido conceitual do termo), não deixam de ser tensionados pelo interesse comercial que articula produtores e consumidores. Nesse sentido, sua presença é determinante - embora não seja exclusiva (existem diversas esferas da vida em sociedade que náo se encontra diretamente vinculada ao mercado: por exemplo, família e religiáo). Filmes, livros, programas de televisão, peças de teatro, músicas on-line, shows, frequência a shopping center. Um conjunto de práticas 
existem no interior de um espaço no qual a predominância dos valores mercantis são inquestionáveis. Se, no século XIX, os artistas podiam dar as costas a esse tipo de injunção, isso se torna impossível no mundo atual. O mercado é uma dimensão intrínseca a um conjunto de manifestaçóes culturais, das galerias de arte em New York aos eventos folclóricos na Amazônia. Por isso, transforma-se em um território controverso, repleto de disputas. Nesse contexto, dois aspectos merecem ser sublinhados: autonomia dos "produtores culturais" (as aspas são propositais) e a relação entre público/privado. A problemática da autonomia é um tema clássico da constelação "culto, cultivado, arte". O artista deve se proteger e se insurgir contra as demandas externas às suas inclinaçóes estéticas. Ou como diz Flaubert:

Quando não nos dirigimos à multidão, é justo que a multidão não nos pague. É economia política. Ora, sustento que uma obra de arte digna desse nome e feita com consciência é inapreciável, não tem valor comercial, não pode ser paga. Conclusão: se o artista não tem renda, deve morrer de fome! [...] Quanto mais se põe consciência em seu trabalho, menos se tira lucro dele. Sustento este axioma com a cabeça sob a guilhotina. Nós somos operários do luxo; ora, ninguém é bastante rico para pagar-nos. Quando se quer fazer dinheiro com sua pena, é preciso fazer jornalismo, folhetim ou teatro. (apud BOURDIEU, 1992, p. I01).

Essa visão radical da autonomia do artista irá se debilitar ao longo do século XX. O desenvolvimento do mercado internacional de arte, o advento das multimídias e das intervençóes, o processo de concentração das editoras, a transformação das livrarias em cadeias de distribuição de livros, o advento do best-seller, redefinem a posição do sujeito artístico no contexto contemporâneo ${ }^{11}$. Uma leitura pessimista (mas sugestiva) da perda da autonomia do artista pode ser encontrada na tradição frankfurtiana. Ela sublinha como a arte cede terreno ao reino da mercadoria. Se no século XIX os artistas podiam encontrar refúgio no território da grande arte, aos poucos ele é penetrado pelos interesses do mercado. Entretanto, se é verdade que a ideia da autonomia se debilita, longe de desaparecer, ela irá se generalizar, podendo ser encontrada em domínios que náo estavam antes contemplados em sua compreensão original. Os "produtores culturais" atuais, que não pertencem necessariamente ao domínio da grande Arte, diante da imposição pura e simples das regras de mercado, enfrentam um problema semelhante ao diagnosticado por Adorno

II Consultar: Raymonde Moulin, 2000. Sobre o mercado mundial de edição, ver: John B. Thompson, 2012. 
e Horkheimer. O termo "produtor + cultural" encerra uma tensão. Contrariamente ao ideal do século XIX, concebe-se a existência de um indivíduo que "produz" alguma coisa, ou seja, a noção de produçáo, inerente ao domínio econômico, estende-se à esfera cultural. Porém, é justamente o fragmento de sentido, "cultural", depositado na camada geológica da constelação negada anteriormente, que irá reintroduzir a tensão entre arte/mercadoria. Fazer filmes, música, peças de teatro, escrever livros, qualquer uma dessas práticas, é sempre tensionada pelas relaçóes de mercado. Ceder ou não às suas imposiçóes é um dilema de todo "produtor".

Mas a questão da autonomia tem ainda outros desdobramentos. Vimos como a discussão sobre cultura popular faz-se no âmbito da construçáo do Estado-nação. $O$ gênio nacional é revelado através da sobrevivência das práticas imemoriais, o saber do povo (folk-lore) é o testemunho de um passado glorioso. É interessante observar que o movimento romântico possui uma influência grande, tanto entre os artistas, quanto entre os que se dedicam à coleta das coisas populares. Mas o sentido dessa influência é distinto. $\mathrm{O}$ artista romântico, ao valorizar a força do Eu, cultiva a noção de individualidade livre; ele é sujeito, revela uma realidade que se desvenda através de sua sensibilidade de criador individualizado. No caso da cultura popular, estamos no polo oposto. Herder introduz uma distinção entre poesia da natureza e poesia da cultura que será amplamente explorada pelo romantismo nacional (KAMENETSKY, 1973). A poesia da natureza seria de caráter intuitivo, é parte de uma sabedoria que não se adquire com o conhecimento formal. Herder (1964) é sensível à poesia medieval, aos cantos de Ossian, a Homero, enfim, épicos que refletiriam a essência de um povo. A poesia de cultura exprimiria o saber dos letrados, a visão egocêntrica do artista. As virtudes da cultura popular provêm do fato de ela ser uma criação coletiva e anônima. Dificilmente a questáo da autonomia poderia manifestar-se dentro deste contexto. As manifestaçóes populares não pertencem a ninguém, pois são o resíduo de uma construção coletiva que anonimamente sobreviveu às intempéries da história. Bastaria aos folcloristas coletá-las na sua pureza e integridade. A expansão do espaço das trocas comerciais inverte esse quadro. Diversas análises sobre a relaçáo entre festas populares e turismo, por exemplo, mostram como os protagonistas desses folguedos populares enfrentam um problema homólogo ao dos artistas (FARIAS, 2011). A realizaçáo do Boi-Bumbá de Parintins e os desfiles 
das escolas de samba no Rio de Janeiro são eventos que indubitavelmente se realizam no interior de um mercado de entretenimento. Por isso, vamos aí reencontrar uma insatisfação em relação à sua comercialização excessiva ("teria o carnaval das escolas de samba se transformado em mercadoria?"); a crítica revela uma preocupação com a autonomia (até onde se pode ir), pois a afirmação do conteúdo (como queria Adorno) esbarra sobre as imposições comerciais. Evidentemente o discurso que legitima esse tipo de crítica fundamenta-se em elementos distintos da constelação da grande arte. Valoriza-se o autêntico, a identidade, a tradição; porém, o contexto no qual essas manifestaçôes se inserem reedita argumentos que antes lhes pareciam estranhos.

Diante da presença das forças do mercado, a relaçáo entre público e privado irá também se modificar. Norberto Bobbio (1995) observa que a "grande dicotomia”: público/privado reveste-se de um significado político e encontra-se intimamente associada ao Estado moderno. Se é verdade que no mundo ocidental, durante séculos, há o predomínio do direito privado, derivado da difusão e recepçáo do direito romano, com o Estado moderno ocorre uma inversão dos sinais. A primazia do público se impóe e fundamenta-se na ideia de que os interesses coletivos se sobrepóem aos interesses individuais. A esfera do público transforma-se, assim, no lugar da política por excelência, este é o espaço que congrega as vozes concordantes ou dissidentes dos cidadáos. A noção de público tem uma longa história, não é minha intenção retomá-la, quero simplesmente marcar sua relaçáo inextricável com a política e retornar à problemática que nos interessa. Quando se olha as constelaçóes de sentido esboçadas vê-se que a relação entre público e cultura não é assim tão evidente. Ela se encontra ausente na Antropologia clássica que recorta seu objeto de estudo de outra maneira, ou seja, a "grande dicotomia" não se aplica ao entendimento das sociedades indígenas. No que se refere à esfera da arte, existe uma clara homologia entre autonomia e mundo privado. Horkheimer (1941) considerava a privacidade burguesa como um espaço de resistência às forças mercantis da industrializaçáo. A proposta romântica, cujo impacto na vida artística é sensível, sobretudo, ancora-se na valorização do indivíduo e da subjetividade. Este traço aproxima o artista da esfera privada. No âmago de seu aconchego, o talento e a criatividade floresceriam. Benjamin dizia que o homem privado habitava um lugar ímpar, o camarote; aí, impassível, ele usufruía a visão do "teatro do mundo". Em uma passagem sobre o colecionador 
e o interior das casas na época de Luis-Felipe, ele diz: "L'intérieur est le lieu de refuge de l'art. Le collecionneur est le véritable occupant de l'intérieur. Il transfigure les objets pour em faire sa chose. Sa tâche est celle de Sisyphe: em possédant les choses il doit les dépouiller de leur carcatère de marchandises" (BENJAMIN, 1986 , p. 31) ${ }^{12}$. Ao se separar do que se encontrava "lá fora", sua residência estaria ao abrigo das intempéries. O vínculo com o público surge, no entanto, quando nos deparamos com a questão da opinião pública e sua relação com a massa. O livro de Gabriel Tarde (1989) é, nesse sentido, sugestivo. O título L'Opinion et la Foule carrega uma certa ambiguidade. O conceito de multidão, em princípio, anularia a ideia de opinião. Afinal ela é homogênea, amorfa, incapaz de congregar a heterogeneidade das inclinaçóes pessoais. Mas Tarde percebe que é o elemento coletivo, capaz de constituir uma corrente de opiniôes individualizadas, que lhe permite caracterizá-lo como público. O exemplo considerado é a imprensa. O jornal é lido por pessoas independentes. No seu silêncio, o indivíduo reflete sobre o que lhe está sendo proposto; mas, a imprensa tem um alcance que atinge, a distância, as pessoas que já não mais se encontram aglomeradas na multidão. Elas partilhariam algo em comum. Há uma estreita relaçáo entre a expansáo da opiniáo pública e os meios de comunicação, Habermas (1978) mostra que no século da burguesia a noção de público consolida-se em espaços como os salóes e os cafés e que o impresso tem um papel fundamental neste processo. $\mathrm{O}$ advento dos meios de comunicaçáo de massa incide diretamente neste quadro. Nos Estados Unidos o debate sobre a opiniáo pública, principalmente junto à Escola de Chicago, é inseparável da emergência dos meios de comunicação; eles seriam capazes de difundir padrôes de pensamento e comportamento em escala ampliada (COOLEY; COOLEY, 1933). Por isso, interessam tanto aos teóricos da Sociologia da modernização. Os meios de comunicação teriam a propriedade de retirar os indivíduos das malhas da tradição, dos costumes, da autoridade patriarcal, dando-lhes a oportunidade de possuir uma opiniáo a ser exercida em um espaço público. Tal processo de individualizaçáo é visto como decorrente da estrutura da própria sociedade moderna. Apesar do debate sobre a opiniáo

12 Na versão em português deste trecho, que consta do texto de Passagens, lê-se: "O intérieur é o refúgio da arte. 0 colecionador é o verdadeiro habitante do intérieur. Ele se incumbe de transfigurar as coisas. Sobre ele recai a tarefa de Sísifo de despir as coisas de seu caráter de mercadoria, uma vez que a possui" (BENJAMIN, 2006. p. 46, nota dos organizadores). 
pública desenvolver-se particularmente com as transformaçóes do capitalismo "pós-industrial" dos anos 1920 e 1940 nos Estados Unidos, não iremos encontrar táo facilmente a noçáo de público no que se refere à cultura de massa. O que se valoriza neste caso é, justamente, a padronização dos bens culturais a serem consumidos em massa. Náo é o indivíduo o centro de seu interesse (os críticos dirão que ela promove uma "pseudoindividualização"). Tampouco o mercado é posto em causa; pelo contrário, a fabricação industrial dos bens simbólicos encontra no espaço das trocas comerciais o seu destino natural. O Estado sempre esteve interessado em desenvolver uma política cultural em relação aos habitantes de um determinado país. Entretanto, a tensão com o mercado náo se apresentava como um elemento problemático. A política do Estado Novo em relaçáo à cultura era marcada pela ideia do nacional. Importava construir uma cultura brasileira capaz de congregar a populaçáo em torno da mesma consciência coletiva. Na França, a criação do Ministério da Cultura por André Malraux tinha como objetivo a democratização da cultura, isto é, o acesso de todos os cidadãos aos bens artísticos e culturais. A temática do mercado era secundária nesses dois exemplos, pois não determinava o foco da intenção política. Com o predomínio dos interesses mercadológicos, expandem-se, em escala global, e a polaridade privado/público adquire outro significado. O domínio do público é cindido entre interesses gerais e interesses particulares do mercado. Se antes o privado era o locus de uma cultura ao abrigo das demandas comerciais, ele passa a se identificar com "privatizaçáo", isto é, uma ação realizada na esfera pública para sacar vantagens particulares. Em contrapartida, a defesa do público recupera parte do argumento da constelação "culto, cultivado, arte" em suas críticas à sociedade de bugigangas (uma qualificação do século XIX). O Estado torna-se assim o lugar da tensão entre público e mercado. Este é um elemento recente do debate contemporâneo, incorporado pelas políticas públicas em relação aos bens culturais.

Outra mudança importante refere-se ao processo de globalização e de mundialização da cultura. Um aspecto envolve a noção de espaço ${ }^{13}$. O advento da sociedade industrial implica transformaçóes substantivas em relação à espacialidade das coisas. Náo é fortuito que a reforma urbana realizada pelo Baron Haussmann seja considerada uma espécie de marco da modernidade.

13 Retomo a argumentação que fiz em outros textos, a exemplo de Um Outro Território (ORTIZ, 1996). 
De fato, o século XIX conhece um rearranjo espacial dos quadros sociais (utilizo uma expressão cara a Maurice Halbwachs) que envolvem os indivíduos nas grandes metrópoles. Neste contexto, a emergência da nação é decisiva. Utilizo o título de um belo livro de Eugen Weber para ilustrar meu raciocínio. Peasants into Frenchman (WEBER, 1976): o texto mostra como os camponeses são transformados em franceses. Esta é a ideia central. Antes da revolução francesa e da revoluçáo industrial eles viviam em suas aldeias, encerrados em aseus costumes e práticas tradicionais. Para se transformarem em cidadáos de um determinado país, deveriam romper o espaço de suas localidades e apreender uma nova maneira de ser. Isso os integraria a um todo, a algo comum a todos: a naçáo francesa. Como tinha anteriormente observado, a modernidade significa um desenraizamento dos indivíduos de suas tradiçóes e origens locais e uma "reterritorialização" no seio do espaço nacional. A nação é uma sociedade que se imagina como uma comunidade. Se as forças da modernidade são centrípetas, tendem a separar os indivíduos uns dos outros. A nação atua como um elemento centrífugo na tentativa de agrupá-los em torno da mesma totalidade. As forças centrípetas da modernidade são contidas no interior do território (no sentido material e figurado) nacional. A globalização rompe este estado de equilíbrio, e a modernidade irá transbordar as fronteiras do nacional para constituir-se enquanto modernidade-mundo. Os antropólogos nos ensinam que as identidades se enraízam sempre em um território geográfico investido de sentido, espaço que pode circunscrever um grupo indígena, uma cidade ou uma nação. Distingue-se, dessa forma, entre um "nós" e um "eles", os que pertencem ou estâo fora do lugar simbolicamente delimitado. $\mathrm{O}$ processo de mundialização da cultura atravessa os diferentes territórios redefinindo o estatuto que o espaço nacional ocupava anteriormente. As noçóes de próximo e distante, autóctone e estrangeiro, interno e externo, decisivas na definição de identidade nacional, desse modo, são ressignificadas. Um exemplo: o Japão ${ }^{14}$. Existe na língua japonesa um par de oposiçôes, wal yo, que sintetiza o contraponto entre o Japão e o Ocidente. Washoku (cozinha japonesa) x yoshoku (cozinha ocidental), wagashi (doce japonês) x yogashi (bolos, tortas), washi (papel japonês) x yoshi (papel ocidental), wafuku (vestimenta japonesa) x yofuku (roupa ocidental), washitsu (tatami) x yoshitsu (móveis

14 Retiro o exemplo de meu livro O Próximo e o Distante: Japão e modernidade-mundo (ORTIZ, 2000). 
ocidentais). $\mathrm{O}$ arroz, quando servido com comida japonesa, é washiki; mas, como acompanhamento de pratos ocidentais, é denominado yoshiki. Marca-se simbolicamente uma maneira de ser japonês em relação ao que lhe seria externo, estrangeiro. Entretanto, no contexto atual, tal dicotomia se enfraquece. Por um lado, vários itens pertencentes ao polo da tradição são abandonados ou utilizados apenas em eventos especiais; é o caso do kimono, pois as calças, paletós, gravatas, vestidos, tornaram-se tão habituais que ficou difícil associá-los a algo alheio à vida dos japoneses. Por outro lado, os produtos de marca transnacionais - perfumes, relógios, sapatos, vestidos - são vistos como um elemento da moda, e não como uma imposição externa a uma eventual identidade nipônica ${ }^{15}$. Outro exemplo, corriqueiro no debate sobre cultura brasileira durante os anos 1950 e 1960. Um argumento recorrentemente utilizado pelos intelectuais do ISEB (Instituto Superior de Estudos Brasileiros) pode ser resumido da seguinte maneira: ao importarmos produtos estrangeiros, como o chiclete ou o cadilac, estaríamos importando o Ser (americano) alheio à nossa brasilidade (CORBISIER, 1959). Dificilmente, no mercado global dos produtos disponíveis, poderíamos sustentar este tipo de raciocínio. A escolha de determinados bens materiais e simbólicos nada trazem de uma essência autóctone (bebe-se um "autêntico" Cabernet fabricado no Chile; a Pizza Hut seria "italiana”; fabrica-se queijo roquefort em Minas Gerais). Os exemplos poderiam ser multiplicados, porque revelam que as fronteiras entre o autêntico e o exógeno se alteraram. Por isso, é possível afirmar que o inglês deixou de ser britânico ou norte-americano para transformar-se no idioma da modernidade-mundo. Como observa De Swaan (2001), ele é língua central em torno da qual giram todos os outros idiomas (De Swaan utiliza o modelo de galáxia para entender a relação das línguas no "sistema global"). Isso somente é possível por que sua origem britânica ou norte-americana torna-se secundária. Foi necessário que a língua inglesa se desterritorializasse de suas raízes para constituir, em seguida, em padrão mundial das trocas linguística. O mesmo ocorre com símbolos e signos que povoam o imaginário coletivo contemporâneo, marcas de consumo, celebridades, pois eles têm suas raízes geográficas debilitadas sendo ressignificadas no contexto da globalizaçáo.

I5 Também a enka, música alçada à categoria de símbolo nacional, como o samba no Brasil, é preterida pelos jovens pela música pop. 
Madonna e o western não são mais norte-americanos; Pokémon e a alta costura de Yamamoto tampouco são japoneses... Assim como as bolsas Gucci, os relógios Armani, as estrelas de Hollywood sáo referências transnacionais que circulam em escala planetária. A nacionalidade desses signos nos remete a um traço identitário débil, destituído de um sentido histórico mais profundo. Isso tem uma implicação imediata no debate sobre a identidade nacional. A configuraçáo "cultura como totalidade" entendia a problemática cultural dentro de uma perspectiva holística. A cultura nacional representaria a totalidade da nação. $\mathrm{O}$ fundamento de toda a discussão em torno da construção nacional (principalmente na América Latina) repousava nesta premissa. Por isso, o Estado sempre foi uma instituiçáo importante no processo de construçáo identitária. O problema é que a globalização coloca em cheque a jurisdição deste mesmo Estado-nação (ele não desaparece, não há o "fim" do Estado-nação). Ele perde o monopólio da construção da identidade. Um conjunto de referências simbólicas transnacionais encontra-se agora disponível para a construção de identidades (por exemplo, no mundo do consumo). No âmbito da modernidade-mundo, a naçáo transforma-se em uma diferença, um local que se contrapóe a outras naçóes. Ela é uma entre outras identidades possíveis. A afirmaçáo do nacional sofre, portanto, a concorrência da esfera transnacional e das diversas identidades construídas no seu interior (regióes, etnias etc.). Sua totalidade é atravessada pelo fluxo de uma cultura mundializada, abrigando ainda as diferenciaçóes que historicamente a marcavam no seu interior. As mudanças ocorridas implicam, também, o surgimento de instâncias de legitimidade em escala transnacional. O Estado-nação foi, durante alguns séculos, o lugar hegemônico de legitimação das açóes coletivas. Ao perder parte deste predomínio, vamos encontrar no território da modernidade-mundo uma série de outras instâncias que passam a servir de referência, de "modelo", para diferentes grupos dispersos no planeta. Isso implica uma questáo de poder, o surgimento de hierarquias que escapam ao controle das fronteiras nacionais. $\mathrm{O}$ processo de desterritorializaçáo rearranja as forças em jogo. $\mathrm{O}$ inglês não é apenas um idioma desterritorializado (uma língua franca), visto que ele ocupa uma posição de destaque. Torna-se a língua em relação à qual os outros idiomas são classificados. Ele "vale" mais do que os outros, pois representa a nova ordem hierárquica do mercado de bens linguístico.

Não se pode esquecer que o processo de globalização reordena o quadro das forças internacionais. A questão não é tanto, como sublinham os analistas 
das relações internacionais, que tenhamos passado de um modelo bipolar para outro multipolar; mas o fato de os países ocuparem novas posiçóes no contexto global. Essas transformaçóes de natureza geopolítica têm implicaçóes na esfera cultural. Foucault costumava dizer que o século XIX caracterizava-se pelo predomínio da história, que o final do século XX teria deslocado tal inclinação para a problemática do espaço. A globalização reativa a metáfora do espaço. Dizemos globalização, sistema-mundo, mundialização. E háA ideia de que o destino humano realiza-se no globo terrestre privilegia uma visão sincrônica e náo diacrônica dos povos. São vários os motivos para que isso ocorra. Um deles tem certamente a ver com o declínio da ideologia do progresso. A noção de progresso ancora-se em uma perspectiva linear do tempo. Ela nos garantia a certeza de se avançar rumo ao futuro. Isso pode ser constatado na discussáo sobre identidade nacional no Brasil e na América Latina ${ }^{16}$. A busca da construção nacional enfrenta um dilema, a ausência ou a incompletude da modernidade almejada. Seria necessário deslocá-la em direção ao futuro, momento no qual a naçáo enfim se realizaria. Nesse sentido, a modernidade é vista como uma conquista europeia, ou seja, na sua essência ela seria ocidental, caberia ao "restante do mundo" ajustar-se ao seu ritmo, preencher a lacuna temporal manifesta neste anacronismo histórico. Mas o que significa declínio? Utilizando uma ideia de Lyotard (1986), eu diria: a ideologia do progresso deixa de ser "um grande relato". Não se trata do seu desaparecimento; entretanto, o relato não mais consegue constituir uma explicaçáo total, um discurso capaz de articular de maneira coerente e orgânica os níveis individual, cultural, social e econômico. Não resta dúvida de que, do ponto de vista tecnológico, a ideia de progresso persiste: um aparelho de DVD é tecnologicamente superior a um videocassete; o telefone celular possui múltiplas utilidades que um telefone fixo desconhece. Passar de uma tecnologia para outra evidencia uma progressão na realização de determinados performances. No entanto, é difícil imaginarmos a noção de progresso como algo que se estenderia a todos os domínios da sociedade. $\mathrm{O}$ avanço tecnológico náo significa necessariamente democracia, igualdade, justiça ou realização pessoal. Se for possível considerarmos a existência de progressos em alguns setores da vida em sociedade, já não mais acreditamos na ideia de uma progressão da história que nos afastaria de um

16 Consultar um liuro "clássico" sobre o tema: El Pensamiento Latinoamericano (ZEA, 1965). 
ponto de origem visto como primitivo e anacrônico (por exemplo, as etapas históricas para Condorcet ou o desenvolvimento do Espírito, para Hegel). Por isso, não faz mais sentido falar em modernidade como um conceito ocidental, o debate se diversifica ao se considerar sua expansão através de realizaçôes históricas distintas ${ }^{17}$. Não é possível ordená-las segundo uma linha de tempo que se fragmentou, as modernidades - realizadas historicamente - encarnam-se em espaços diferentes, desenhando um novo quadro da relação entre povos e países. O declínio da ideologia do progresso contém, ainda, outra dimensáo: a crítica ao eurocentrismo ${ }^{18}$. A herança iluminista tinha nos ensinado a perceber a história de maneira evolutiva, "o fim da história" coincidiria com a realização das virtudes do mundo ocidental. Por isso, a modernidade era vista como ocidental na sua "estrutura" (como a considera Weber, na "introduçáo" de A Ética Protestante e o Espírito do Capitalismo). A ruptura da cadeia do tempo retira do ocidente a primazia de nos orientar em relação ao futuro. Logo, a ilusão da superioridade da cultura ocidental se desfaz, deixa de ser o único parâmetro de referência no debate intelectual. Essas transformaçóes não ocorrem apenas no plano das ideias. Como tinha observado, o processo de globalizaçáo incide diretamente nas forças geopolíticas que determinam o cenário do mundo contemporâneo. $\mathrm{O}$ oriente, antes relegado ao plano de uma história estática (Hegel dizia: repetitiva, imóvel), irracional, torna-se uma força importante no quadro internacional (Japão, China, Tigres Asiáticos). Também os países "emergentes" (dos quais o Brasil faz parte) alteram a situaçáo anterior. Isso significa que o relato eurocêntrico perde em força simbólica e em materialidade. Tem-se, assim, uma alteração importante no movimento de construção das identidades nacionais. $\mathrm{O}$ referente de alteridade modifica-se. Um exemplo: o pensamento brasileiro. Isto é, o conjunto de autores que tradicionalmente tem se debruçado sobre nossa história para explicar o Brasil. A alteridade constrói-se em relaçáo ao europeu e ao norte-americano. Na verdade, certa Europa (França, Alemanha, Inglaterra), figura que representaria sem equívocos a realização da modernidade. $\mathrm{O}$ estrangeiro é sempre o alter-ego de um espelho no qual se reflete nossas deformidades. Com o processo de globalização, temos uma multiplicação dos referentes (não são infinitos, nem neutros). $\mathrm{O}$ elemento

17 Eisenstad (2007) fala em modernidades-múltiplas.

18 A partir dos anos 1980 surge uma imensa literatura que se ocupa do tema. Remeto o leitor a dois liuros de Jack Goody (1996, 2006): The East in The West $e$ The Theft of the History. 
ocidental permanece, mas já não mais desfruta uma posição incontestável no cenário mundial. O Outro vem marcado pelo cruzamento de olhares distintos no espaço da modernidade-mundo.

Por fim, um tema controverso, as transformaçóes na esfera da política. O contraste com as constelaçóes de sentido nos ajuda a compreender algumas delas. O tema da política é reiteradamente denegado pelo universo da Arte. O ideal flaubertiano exigia uma autonomia radical do campo artístico. Essa autonomia deveria ser preservada a todo custo, pois as ambiçóes políticas constituiriam uma ameaça, viriam a confundir as fronteiras de atividades em si incompatíveis. Por essa razão, Sartre (1948) afirma que Flaubert não escreve nem para a aristocracia, nem para a burguesia, nem para a classe operária ou, como diz Barthes, caso isso acontecesse, "o universal lhe escaparia". O preço para alcançar a universalidade residiria no recolhimento em relação ao mundo. Este será um constante ponto de fricção na discussão em relação às vanguardas artísticas. Elas querem justamente inserir a arte no mundo, torná-la presente entre os homens, anunciar o futuro. O que se encontrava separado da vida deveria ser imerso nas contradiçôes históricas. A Antropologia clássica tampouco se interessava diretamente pelo tema. Os costumes e rituais indígenas faziam parte de um universo no qual ele era um assunto secundário. Claro, os estudos etnológicos abrangiam as formas de governo (chefia, clâ, autoridade) e de organização das sociedades indígenas, o que na língua inglesa se expressa através do termo polity. Entretanto, as contradiçóes propriamente políticas ficavam fora de seu alcance ${ }^{19}$. Até os anos 1950 e 1960, os antropólogos tinham uma enorme dificuldade em trabalhá-las, daí a ambiguidade da literatura existente em relação ao colonialismo (o malabarismo teórico para aceitá-lo e justificá-lo fazem hoje parte do arquivo da história da disciplina ${ }^{20}$. Entretanto, se a política manifesta-se de maneira incidental nessas duas constelaçóes de sentido, as coisas se passam de outra forma ao analisarmos a cultura de massa ou cultura nacional. No primeiro caso, o problema da democratização manifesta-se em torno da oposição elite/povo. A tensão entre superior/inferior, bom gosto/ mau gosto, alto/baixo, refinamento/mediocridade, adquire outra conotação:

19 Um liuro que faz uma análise exaustiva do tema da política na história da Antropologia é o de Joan Vincent (1990), intitulado Anthropology and Politics: visions, traditions, and trends.

20 Por exemplo, o dilema que os antropólogos franceses enfrentam na Argélia. Ver: Fabien Sacriste, 200 I. 
elitismo/democratização. A cultura de elite ou a alta cultura (high culture) se restringiria a poucos, os privilegiados; a popularizaçáo dos bens culturais (difusão das obras consagradas na esfera culta), assim como as novas formas de consumo de massa (revistas em quadrinho, shows de auditório, programas de televisão), integraria a todos dentro de um mesmo padrão cultural ${ }^{21}$. Nesse sentido, a emergência da sociedade de massas é vista por muitos como uma ampliação da democracia, nela os bens simbólicos não mais circulariam em espaços restritos enfraquecendo desta forma a segmentação social. Por isso, a televisão transforma-se no ícone de uma época, porque representa um artefato moderno e um meio eficaz de nivelamento cultural e afirmação "democrática". Eu havia dito que o vínculo entre técnica e cultura tinha se estreitado na medida em que os bens culturais eram mediados pelos objetos técnicos. Pode-se afirmar que, desde o século XIX, uma dimensão da política começa a se exprimir enquanto atributo da técnica. Por exemplo, o embate envolvendo pintores e fotógrafos. Os que se encontravam no polo da grande arte consideravam a "democracia do retrato" uma arte de quatro tostóes colocada à disposição de uma sociedade de barateamento e de bugigangas. Em contrapartida, os fotógrafos argumentavam que, por ela ser arte e indústria, promoveria uma democratização do acesso às imagens. Esta associação entre técnica e política, ainda embrionária durante o advento da revolução industrial, irá se reforçar a ponto de tornar-se uma espécie de senso comum no debate contemporâneo. Quando nos debruçamos sobre a história dos meios de comunicaçáo, vamos reencontrá-la em situaçóes diversas: pintura $\mathrm{x}$ fotografia; literatura $\mathrm{x}$ romance folhetim; teatro $\mathrm{x}$ cinema; teatro/literatura $\mathrm{x}$ rádio; teatro/cinema $\mathrm{x}$ televisão. Cada um desses pares antagônicos pode ser ordenado segundo uma polaridade maior: elitismo/democratização. Nesse sentido, a fotografia seria "mais democrática" do que a pintura; a televisão "mais democrática" do que a literatura. Hoje não hesitamos em considerar a internet como um espaço democrático em contraposição à televisão, símbolo falido de uma era de massas.

A constelação de sentido na qual a política manifesta-se com toda a sua força é certamente a vinculada ao Estado-nação. Existem, neste caso, duas dimensóes que devem ser levadas em consideraçáo: externa e interna. $\mathrm{O}$ século

21 Este é um debate forte entre os intelectuais nos Estados Unidos nos anos 1950. Ver: Jacobs, 196I; Rosemberg e White, 1957. 
XIX é o século das naçóes, entretanto, o espaço internacional estrutura-se segundo uma clara hierarquia na qual se articulam centro e periferia. Hobsbawm (1988) observa que este é o momento no qual é criada uma economia global que progressivamente atinge as mais remotas paragens do mundo; a função das colônias e dos países dependentes era simplesmente complementar às economias das metrópoles e não lhes fazer concorrência. A emergência da sociedade industrial, que inicialmente desenvolve-se em uma parte da Europa, em seguida nos Estados Unidos e Japão, reorganiza o antigo quadro de dominação herdado dos séculos anteriores. Ao lado das antigas colônias, principalmente do império britânico (também de um pequeno país como Portugal), o colonialismo irá se expandir e se fortalecer (FERRO, 1999). Um exemplo: a partilha da África negra. Através de um "acordo de cavalheiros", ela foi dividida entre os principais países europeus, inclusive os que não possuíam uma sólida tradição colonialista (é o caso da Alemanha). O final do século XIX conhece, ainda, uma reestruturação profunda do capitalismo. Os interesses econômicos descolam-se das relaçóes propriamente colonialistas, ou seja, deixam de ser o empreendimento de uma minoria branca nas colônias, para ganhar outro contorno. $\mathrm{O}$ conceito de imperialismo exprime justamente esta mudança. Hobson (1902) dirá que esta forma recente de dominação ampara-se na aliança entre o Estado e as forças industriais e financeiras. Países como os Estados Unidos e o Japáo, que tradicionalmente não participavam de açóes colonizadoras, com a industrialização crescente, irão cada vez mais inserir-se neste movimento de alargamento das fronteiras. A nação torna-se a categoria central para a organização e a legitimação deste expansionismo. Por isso, tanto o colonialismo quanto o imperialismo estáo intimamente associados à ideia de nacionalismo. Portadora das virtudes civilizatórias, a nação teria a missáo de educar os homens incultos, retirando-os de sua condição de infantilidade e regressão. Caberia aos países industriais, compostos por "raças superiores", o dever moral de ensinar às "raças inferiores" o caminho correto a ser percorrido. Isso terá consequências no plano cultural. Os escritos de Franz Fanon são exemplares a esse respeito. A dominação colonial coloca em conflito dois grupos antagônicos, o colonizador e o colonizado. Entre eles, não haveria nenhum ponto em comum. O choque seria inevitável, pois ambos vivem uma situação na qual as contradições não podem ser escamoteadas. A esfera cultural transforma-se, dessa forma, em um campo de batalha, um fronte político. 
De um lado, estabelece-se a cultura do colonizador, que tende a persuadir os nativos, aliená-los de sua realidade social; de outro lado, um movimento de resistência que se opóe ao que é estrangeiro. Fanon percebe a cultura exógena como uma alienação. Nela se espelha o Ser deformado do colonizado. Sem se reconhecer a si mesmo, ele se distancia de sua "verdadeira" essência sendo e éincapaz de se realizar enquanto homem livre. O processo de libertação ocorreria pelo engajamento na construção da cultura nacional. Somente dessa maneira os subalternos escapariam das malhas de um destino ditado pelos outros. A problemática do colonialismo cultural é fundamentalmente uma questáo política. Ela toma formas diferentes em função dos contextos históricos, da relação de forças entre os grupos em disputa, da organização social, mas encerra um elemento que transcende as particularidades de cada país: a oposição entre cultura exógena e cultura nacional. Se a nação é o instrumento de dominaçáo no polo do colonizador, ela se torna o elemento de libertaçáo quando apropriada pelo colonizado. Esta oposiçáo entre o nacional e o estrangeiro, o autóctone e o alienígena, marca também o debate sobre o imperialismo cultural. A noção é mais tardia, e tudo indica que surge em meados dos anos 1960, no âmbito latino-americano. Ela corresponde a um conjunto de mudanças vinculadas à organizaçáo e a difusáo da cultura de massas. Tradicionalmente, a ideia de imperialismo aplicava-se, sobretudo, ao domínio econômico. $\mathrm{O}$ advento dos grandes monopólios constituiria uma nova forma de poder em escala internacional (Lenin dizia ser esta uma fase superior do capitalismo). A produção industrial da cultura, a presença e o controle das tecnologias neste processo, o peso do capital na esfera de entretenimento, impulsionam as multinacionais de cultura para fora de suas fronteiras nacionais. Este é o caso dos Estados Unidos. Seus produtos industrializados invadem o mundo: filmes (Warner Bros, Universal, United Artist, Columbia), programas de televisão (Bonanza, El Gran Chaparral), material impresso (Time, Reader's Digest), peças publicitárias (Mc Cann Erickson, Tompson, Ogilvy). A presença dessa cultura americana torna-se a tal ponto evidente que um autor como Jeremy Tunstall (1977) propóe uma interpretação linguística para compreendê-la. Diante da pergunta: por que os americanos dominam o mercado de publicidade, histórias em quadrinho, filmes, ediçôes? Ele não hesita em atribuir à língua inglesa uma qualidade superior a outras. The Media are American, título de seu livro, considera que o inglês, devido ao fato de ser mais "simples" 
e "direto" do que qualquer outro idioma, seria o elemento mais apropriado para se veicular mensagens através dos meios de comunicação. Na sua natureza, ele constituiria a língua da racionalidade e da modernidade. Tudo se passa como se a base material do imperialismo econômico fosse completada por uma superestrutura no nível do simbólico. O Pato Donald torna-se o ícone de uma cultura de entretenimento cujo objetivo seria promover os valores e os ideais americanos. A leitura ingênua das histórias em quadrinho reforçaria o complexo de inferioridade dos países periféricos (MATTELARD; DORFMAN, 1973). Dentro desta perspectiva, a esfera da comunicaçáo transforma-se em um lugar estratégico para o exercício da hegemonia. Particularmente, na América Latina surge uma vasta literatura crítica desta "nova ordem internacional da informação". Os autores sublinham que a difusáo cultural faz-se em uma via de máo única, acentuando a dependência da periferia em relação à metrópole (MATTELARD, 1976; BELTRÁN; CARDONA, 1980; VARIS; NORDENSTRENG, 1974).

No plano interno, a afirmação da identidade nacional permanece, como o foi no XIX, uma questão importante. Na Alemanha, o vínculo entre cultura e política é decisivo no processo de construçáo nacional a ponto de Lepenies (2006) citar que a cultura era uma espécie de "nobre substituto" da política, porque eenvolvendo intelectuais, artistas, escritores. O destino das artes e letras encontrava-se inextricavelmente mesclado ao destino da nação. Na França, o Estado tem um papel de relevo na fabricaçáo de signos que representam $L a$ République. Uma política ativa envolve a criação de museus, onde repousam a glória nacional, a valorização do patrimônio histórico e das tradiçóes populares, a difusão dos grandes nomes de artistas e escritores pelos manuais escolares. Um exemplo de "invenção da tradição" é Marianne (deixa AGULHON, 2001). O que significa esta mulher "à bonnet phrygien" (deixar em francês)? Sua história nasce na revolução quando os republicanos decidem utilizar a figura da Liberdade como representaçáo do Estado. Marianne, a mulher que no meio da multidão avança em combate, brandindo uma imensa bandeira tricolor, nasce como uma representação imagética da ruptura em relação ao Antigo Regime. Ao longo dos anos sua figura será reinterpretada pelas razóes deste mesmo Estado; pintores e escultores irão "rotinizar o seu carisma" através dos monumentos erigidos nas cidades e municípios franceses. A Liberdade, materializada enquanto escultura, pintura, desenho, fotografia, transforma-se 
assim em crença popular. No contexto latino-americano, a relação entre cultura e política associa-se, sobretudo, à construção da modernidade. Por isso, o ideal flaubertiano da "arte pela arte" é inapropriado. O universo artístico encontra-se imerso nas contradiçóes do presente e na formulaçáo do futuro; o artista está sempre comprometido com um projeto político que o interpela como homem engajado. Os muralistas mexicanos retratam as contradiçóes de uma sociedade de classes, querem romper com o passado oligárquico e patriarcal; Brasília, de Niemeyer e Lúcio Costa anuncia, em uma região despovoada e árida, a modernidade ainda ausente em inúmeras regióes do país. O Estado-nação é construído no presente, mas visa ao futuro. $\mathrm{O}$ drama da modernidade incompleta, da contraposição ao estrangeiro, do complexo de inferioridade em relação à metrópole, da oposição entre autóctone e estrangeiro, domina o pensamento latino-americano do século XIX até as formulaçóes da teoria da dependência. Como observa Octávio Ianni (1993), o esforço para se diagnosticar os males do continente tem como objetivo exprimir a "metamorfose da população em povo". Como povo é uma categoria política, cultura não pode deixar de manifestar-se também como coisa política. No momento em que imperam as teorias raciológicas (ok) europeias (são todas racistas), o dilema é sair do impasse que condena um povo mestiço à condição de inferioridade. Autores como José de Vasconcelos no México e Gilberto Freyre no Brasil procuram escapar desta armadilha, ao promoverem o mestiço como representante da "quinta raça" ou da mistura harmoniosa dos povos (LARRAÍN, 1996). O problema recoloca-se durante o período desenvolvimentista. Para superar o subdesenvolvimento seria preciso formular uma ideologia capaz de mobilizar as forças políticas em uma determinada direção. Tínhamos de "tomar consciência" de nossa situaçáo de precariedade e superar o quadro adverso que nos aprisionava. A ideologia do desenvolvimento antecede ao próprio desenvolvimento; ela organiza e projeta o futuro. Os movimentos culturais dos anos 1950 e 1960 na América Latina estão profundamente impregnados deste tipo de entendimento. No caso brasileiro, retomo o texto paradigmático de Glauber Rocha (1979): "Estética da Fome". Em meados dos anos 1960, ele escreve um contundente manifesto contendo um diagnóstico da sociedade brasileira e do cinema novo. Caberia aos cineastas retratarem a miserabilidade do país, uma vez quesomente desta forma escapariam aos grilhóes do cinema colonial imposto pela dominação estrangeira. A arte cinematográfica encontraria, 
enfim, seu estatuto estético e político de libertação. Para isso, era necessário uma "tomada de consciência", pelos artistas, das verdadeiras contradiçôes sociais do país; e, com seus filmes engajados conseguiriam "despertar a consciência" de um público adormecido, alienado da realidade denegada. Chamo a atenção para a dimensão da consciência que aflora neste exemplo. Ela não é uma inclinação pessoal de um autor ou de um artista. Na verdade, atravessa todo o debate da época. É na esfera da cultura que se inscreve a consciência; aí se joga o destino nacional. Cinema, teatro, música, artes plásticas, arquitetura seriam manifestaçóes que contribuiriam para a superação da condição alienada. Uma das mudanças substantivas em relação ao quadro, anterior refere-se à dimensão da consciência. Eu diria que a partir de maio de 1968, dos movimentos estudantis da década de 1960 nos Estados Unidos e na Alemanha, do movimento hippie e do feminismo, a esfera da cultura torna-se um lugar de poder. Durante as manifestaçóes estudantis na França, havia um curioso grafite escrito nos muros dos edifícios: “métro, boulôt, dôdô" (metrô, trabalhar, dormir). A crítica feita pelos estudantes rebeldes pode ser resumida desta maneira: não é no nível da consciência que se dá a reprodução da ordem. De nada adiantaria conscientizar a classe operária de sua alienaçáo social, pois a questão do poder inscrevia-se no cotidiano: tomar o metrô, ir trabalhar, voltar para casa, dormir e, no dia seguinte, retomar este ciclo infernal. $\mathrm{O}$ mesmo pode-se mencionar sobre dos movimentos estudantis americanos: o cabelo comprido, as sandálias, fumar maconha, tomar LSD, ouvir música pop, enfim, um conjunto de práticas sociais é investido de sentido político. Um exemplo: o feminismo. Consideremos a irônica descrição que Betty Friedman faz da condição da mulher americana:

The suburban housewife - she was the dream image of the young American women and the envy, it was said, of women all over the world. The American housewife - freed by science and labor saving appliances from the drudgery, the dangers of childbirth and the illnesses of her grandmother. She was healthy, beautiful, educated, concerned only about her husband, her children, her home. She had found true feminine fulfillment. As a housewife and mother, she was respected as a full and equal partner to man in his world. She was free to choose automobiles, clothes, appliances, supermarkets; she had everything that women ever dreamed of. (FRIEDMAN, 1963, p. 18)22. (citar a tradução em português)

22 "A dona de casa do subúrbio - ela era a imagem de sonho das mulheres americanas jovens e a inveja, diziase, das mulheres em todo o mundo. A dona de casa americana - alforriada pela ciência e por aparelhos 
As relações de dominação manifestam-se e reforçam-se através da rotina, dos hábitos: comprar roupas, ir ao supermercado, ter uma casa bonita, entreter o marido. Elas permeiam essas ações repetitivas; porém, cheias de sentido. O tema da consciência restringia a política às instituiçóes nas quais ela se realizava: Estado, partido, sindicato, movimento social. Agora, a problemática atravessa as relaçóes sociais e toma uma configuração insuspeitada. Ao longo dos anos 1970 e 1980 essa dimensão é em boa parte incorporada pela sociedade de consumo, na qual diversas expressóes, concertos de rock, hip hop funcionam como uma espécie de "rituais de rebeliaão" (para usar uma terminologia de Gluckman). É interessante observar que, durante os anos 1960 e 1970, há, no âmbito das Ciências Sociais, um deslocamento do plano da consciência para o da estrutura o que se estaria oculto. A noçáo de épistémè, em Foucault (1966), tem justamente a intenção desvendar a existência da estrutura subjacente dos códigos que fixam a ordem empírica; ela escaparia ao alcance das voliçôes pessoais, determinando, de alguma maneira, as possibilidades do pensamento. Em Les Mots et les Choses, ele demonstra que cada época teria uma épistémè específica, isto é, um conjunto de hipóteses, métodos, problemáticas que fundamentariam o discurso científico. Os pensadores dessas épocas atuariam em um terreno pré-fixado constituindo um "réseau imperceptible de contraintes". Foucault (1996) analisa três momentos diferentes: renascença, épocas clássica e moderna. Seu objetivo é elaborar uma arqueologia do solo epistemológico no qual se sustenta o arcabouço do discurso científico de um determinado momento histórico. Não se trata das teorias existentes, pois essas são explícitas, mas do alicerce no qual são erigidas. Também a noção de habitus em Bourdieu (1972) é sugestiva. Enquanto "estrutura estruturada", isto é, categoria de classificação do pensamento, incorporada pelo indivíduo no processo de socialização, ele funcionaria como um conjunto de princípios que formatariam a ação. $\mathrm{O}$ habitus não implica necessariamente uma dimensão consciente (um valor, como pensava Weber), mas algo que se inscreve no corpo e na trajetória dos indivíduos. Um exemplo: o gosto. Ele é o resultado

poupadores de trabalho, liberta dos perigos do parto e das doenças de sua avó - ela era saudável, bonita, educada, preocupada apenas com seu marido, seus filhos, seu lar. Havia encontrado a verdadeira realização feminina. Como dona de casa e mãe, era respeitada como parceira plena e igual ao homem em seu mundo. Ela era liure para escolher automóveis, roupas, eletrodomésticos, supermercados; ela tinha tudo que as mulheres sempre sonharam ter" (Nota dos organizadores). 
do cruzamento das disposiçóes internas de cada um (materializada no habitus) e de sua posiçáo social. Escolher o concerto para a mão esquerda de Ravel (o compositor o escreveu para um amigo pianista que havia perdido a máo direita) náo é simplesmente uma questão de gosto: é necessário que o ouvinte possua um capital cultural aprimorado, conviva em uma rede de relaçóes sociais e estéticas, capaz de orientá-lo neste tipo de escolha. $\mathrm{O}$ habitus o situa na trama imperceptível de "imposiçôes", constituindo sua segunda natureza. Esses autores afastam-se da tradição intelectual que via a problemática da política imersa na questão da consciência. Por exemplo, Lukács (consciência de classe) ou o existencialismo sartriano (o indivíduo que toma consciência de sua condição alienada). Agora, as relações de poder manifestam-se nas práticas, nas maneiras de ser, inscrevendo-as no âmago do simbólico. Não se trata propriamente de uma politizaçáo do universo cultural, tampouco de uma invasão da cultura na esfera política. As relaçóes de poder são imanentes à vida social, podem (ou não) serem investidas de um sentido político.

Um exemplo é o debate em torno das identidades. Tem-se, às vezes, a impressão de que a problemática da identidade é tratada como algo inteiramente novo no mundo contemporâneo. Um autor como Stuart Hall (1992) considera que ela deriva, em boa parte, da existência de um sujeito pós-moderno habitante da modernidade tardia. Em parte, essa concepção é verdadeira. Entretanto, não explica por que as reivindicaçóes identitárias encontram suporte justamente nos grupos de imigrantes na Europa e nos indígenas na América Latina. Ou seja, entre as populaçóes que se encontram à margem ou integradas de maneira fraturada nesta hipermodernidade em curso. Eu havia proposto em meu livro Cultura Brasileira e Identidade Nacional uma distinção conceitual entre memória coletiva popular e memória nacional. Retomo minha argumentação para desenvolver a relação entre cultura e política. Halbwachs mostra que a memória coletiva encontra-se enraizada no grupo, as lembranças existem e são ativadas em função da dinâmica dos membros que o compóem. É o caso do candomblé e das festas folclóricas. Encontramo-nos diante de uma peça teatral de enredo único na qual a memória é periodicamente celebrada; assim, o rito é a forma através da qual as lembranças são materializadas. Mas a memória coletiva dos grupos é da ordem da vivência, enraíza-se no cotidiano das pessoas e as envolve nas suas relaçóes recíprocas. Já a memória nacional é uma construção de segunda ordem, é produto da história e dos 
conflitos sociais, e o popular ao qual se refere não coincide com a vivência de um grupo particular. Trata-se de uma representação que transcende todos eles. A memória opera, portanto, uma transfiguração simbólica da realidade social, integrando os habitantes de um determinado país dentro de sua totalidade. O Estado é sua referência privilegiada. Como entre a ordem da vivência e a ordem da representação nacional existe um hiato, é necessário que entre elas atue um elemento intermediário. São os intelectuais que desempenham esta funçáo de mediadores simbólicos. Saussure diria que eles transformam o popular em significante de um significado maior: a nação. $O$ processo de construção da identidade fundamenta-se em uma interpretação que estabelece um vínculo entre o singular e o universal, isto é, a totalidade nacional. Os mediadores simbólicos, como os intelectuais orgânicos para Gramsci, são os artífices de um relato comum; tecem um discurso coerente e articulado, conferindo sentido a uma realidade dispare e fragmentada. Eu havia dito que, no contexto da modernidade-mundo, o Estado-nação perde o monopólio da construção da identidade; ele é simultaneamente ameaçado pelas forças internas e transnacionais que atravessam o seu território. Entretanto, apesar da matéria trabalhada pela representação simbólica ser outra, o mecanismo de construçáo identitária permanece inalterado. A identidade é sempre uma construção simbólica que se faz em relação a um referente. Neste caso, a nação cede lugar ao referente étnico, regional, de gênero ou de grupo. Este tipo de labor simbólico necessita dos mediadores aos quais eu me referia São eles que modelam e "contam" a realidade. Movimentos indígenas, quilombolas, feministas são integrantes da vida política na medida em que traduzem, na arena da sociedade civil, os dilemas da cultura como lugar de poder. Sua legitimidade erige-se sobre o alicerce da esfera cultural. "Preservar as crenças indígenas", "cultivar as raízes afro-brasileiras", "denunciar as armadilhas do machismo"; mas, sobretudo, elaborar uma versão distinta da história narrada a partir de novos sujeitos. Um dos papéis centrais desses mediadores simbólicos é retomar o passado com outros olhos, retirando-o da leitura tradicional na qual se encontrava aprisionado. A partícula "a partir" (do ponto de vista negro, indígena, feminista, dos grupos subalternos) é imprescindível para a afirmação das reivindicaçóes que se fazem no presente. Entretanto, o hiato que existia entre memória nacional e memória coletiva popular, não desaparece. Pelo contrário, é reeditado na relação complementar e tensa entre esses intelectuais orgânicos 
e a realidade ressignificada. Os movimentos negro ou feminista não coincidem com a vivência dos negros ou das mulheres, a defasagem entre essas duas ordens de eventos náo se encontra apagada pela simples existência da identidade construída. Ela é matéria de disputa entre os mediadores simbólicos e os que por ela se veem representados. A questão identitária possui, portanto, uma dupla face. A primeira, mais visível, é pública. Trata-se do confronto que se desenvolve no seio da sociedade civil: movimento negro em busca de sua afirmação contra o racismo; movimentos indígenas na preservação de suas tradiçóes etc. A segunda é de outra natureza, desvenda-se na relação contraditória entre a matéria desta identidade construída e os intelectuais orgânicos que a representam. As relaçóes de poder são, dessa forma, codificadas de maneira distintas em função da ordem nas quais elas se inserem.

Um último aspecto da relação entre cultura e política merece ser sublinhado: a questão da diversidade. É um tema que não fazia parte da tradição intelectual anterior. A problemática da diversidade tornou-se importante no século XXI, por que o mundo se globalizou. E é no interior da unicidade do planeta que o diverso encontra um estatuto que desconhecia (ORTIZ, 2015). Isso significa que o termo encerra uma dimensão valorativa. De maneira resumida, pode-se afirmar dizer que vivemos um momento em que o universalismo é visto com desconfiança e a diversidade é apreciada como virtude. A palavra é polissêmica sendo apropriada por grupo de interesses distintos e com objetivos antagônicos (basta lermos a literatura que se ocupa da administração de empresas e dos negócios). Mas o relevante para nossa discussão é que "diversidade", enunciada no singular, nos remete a ideias positivas: pluralismo, democracia, tolerância etc. Ela se torna, assim, um emblema da modernidade-mundo e sua matéria de ignição é a cultura. Diversidade alude a um princípio abstrato atualizado em objetos tangíveis: idiomas, rituais religiosos, danças, músicas, filmes, concepçóes de mundo. Mas, para que seja reconhecida de maneira legítima - isto é, fonte de autoridade -, é necessário transformar-se em um "valor universal" (UNESCO, 2001). Ao ser definida desta maneira, torna-se imediato sua aproximaçáo a outros valores universais, por exemplo, os direitos humanos. Este tour de force simbólico, que nos parece natural, é algo recente. Consideremos o exemplo da Antropologia. Em 1947, durante a preparaçáo da Carta de Direitos Humanos da ONU, um grupo de antropólogos liderados por Melville Herskovits é convidado para escrever um documento a respeito dos povos indígenas. Eles chegam à seguinte conclusão: 
Os padrões e os valores são relativos às culturas dos quais eles derivam, assim, qualquer tentativa de se formular qualquer tipo de postulado que decorra de um código moral e de crenças de uma única cultura, deveria ser excluída da aplicabilidade de qualquer Declaração dos Direitos Humanos dirigida à humanidade como um todo ${ }^{23}$.

Ou seja, o conceito não se aplicaria à realidade indígena. $\mathrm{O}$ raciocínio dos autores fundamenta-se no relativismo cultural antropológico. Cada cultura seria uma entidade idiossincrática; por isso, os valores morais, sendo também culturais, variariam em função da diversidade cultural. Seria impossível encontrar uma unidade de medida capaz de ser aplicada a esta miríade de pontos descontínuos. No quadro atual, ocorre uma clara inversão dos sinais: as culturas indígenas devem ser respeitadas e defendidas por que fazem parte dos "direitos humanos". A desconfiança em relação ao universalismo é, neste aspecto, minorada. É preciso valorizar a parte no interior do todo. A preservação de seus costumes, idiomas, ritos, mitologias, transforma-se em sinônimo de preservação do patrimônio da humanidade. Esta operação é plena de sentido político. Há, primeiramente, o aspecto jurídico a ser considerado, ou seja, como elementos da esfera cultural, são arbitrados pelos princípios e regras do Direito. Ao se consultar o Direito Internacional, observa-se que existem uma série de cláusulas: a obrigação de se respeitar a herança cultural durante os conflitos armados; a obrigação de se abster e de transferir a herança cultural de um território ocupado militarmente; o princípio de cooperação, em tempo de paz, de prevenir o tráfico ilícito de objetos culturais (BORELLI; LANZERINI, 2012; STAMATOPOLOU, 2007). Existe, inclusive, um princípio de "proteção às culturas vivas". Outro aspecto diz respeito à antinomia entre indivíduo e coletividade (LYONS; MAYALL, 2003). Tradicionalmente, a Declaração Universal dos Direitos Humanos privilegiava o direito individual; porém, na medida em que o problema dos direitos torna-se cada vez mais complexo, outra vertente interpretativa irá incidir sobre o direito dos grupos (indígenas, minorias, mulheres etc.). Ao aproximá-los dos direitos culturais, um passo é dado na direção de se considerar a cultura como o espaço de sua realização. Entretanto, independentemente das implicaçóes jurídicas, é a dimensão política que emerge como central na noção de direitos, pois confere aos grupos sociais a possibilidade de reivindicar de maneira legítima uma

23 Ver: Statement on Human Rights (AMERICAN ANTHROPOLOGICAL ASSOCIATION, 1947). 
condição denegada pela sociedade. A associação entre diversidade cultural e direitos situa as manifestaçóes culturais em um quadro de referências antes desconhecido. Alguns autores como Taylor e Honneth procuraram desenvolver uma teoria do reconhecimento para dar conta dessas expressóes emergentes no campo da política (TAYLOR, 1994; HONNETH, 2010). A política da diferença seria uma forma de se equilibrar as distorçôes sociais e as discriminaçóes relativas a uma cidadania de segunda classe. A noção de cidadania é chave na compreensão deste processo. Todavia, ela não se confina à questáo do reconhecimento, o direito de ser diferente. $\mathrm{Na}$ verdade, as expressóes culturais tornam-se uma forma privilegiada de se "fazer política". No contexto latino-americano, no qual as desigualdades sociais são imensas, a cidadania é foco de tensão permanente na sociedade civil. A disputa em torno de sua validade envolve diferentes grupos e camadas sociais, cobrindo domínios inteiramente distintos da vida em sociedade. Um exemplo: a luta dos mayas na Guatemala. A emancipação em relação ao espanhol é traduzida como uma exigência de cidadania capaz de lhes assegurar uma identidade etnolinguística. Mas também manifestaçóes como o hip-hop na periferia das grandes cidades ou os vídeos realizados por jovens vivendo nas favelas urbanas fazem parte das demandas de direitos culturais. Basta olharmos a literatura escrita sobre o tema para nos darmos conta de que a noção de cidadania cultural encontra-se associada aos movimentos indígenas, às políticas de comunicaçáo, à educaçáo escolar, ao patrimônio cultural dos grupos populares, aos jovens vivendo nas grandes cidades etc. Tem-se, assim, um leque de demandas díspares, não necessariamente coincidentes entre si, travadas em torno de um princípio comum. Não é apenas o diverso que entra em linha de consideração, uma multiplicidade de eventos adquire uma conotaçáo política desde que culturalmente demarcados como "questôes de poder".

O que é cultura? Procurei evitar a pergunta ao desenvolver minha argumentação. Creio que o equívoco náo se encontra na reposta apresentada ao problema, a dificuldade maior reside na aceitação implícita do a priori da existência de uma cultura no singular. Náo se trata de considerar o plural como um valor em si, tornou-se certa moda intelectual valorizar tudo o que é diverso, como se isso fosse sinônimo de democracia e pluralismo. 
A questáo é de outra natureza. Retomo um debate esquecido restrito talvez ao âmbito da especialidade antropológica. Quando Tylor (2010) define o conceito de cultura, ele esboça a ideia de uma ciência da cultura. Seu projeto é embrionário, mas será levado a sério pela Antropologia Cultural norte-americana, a qual nutre a ilusáo de fundar uma Teoria da Cultura. A cultura total (o termo é de Boas) de uma sociedade seria um todo orgânico que transcenderia os seus componentes. Por isso, o conceito de caráter é particularmente sedutor para esta tradição de pensamento. Analogamente ao indivíduo toda cultura possuiria uma identidade, um caráter coletivo. Ele é o traço específico que condensaria os atributos de um determinado grupo social (BENEDICT, 1967). Caberia ao antropólogo decifrá-lo. A escola de Boas, ao definir cultura de maneira holística, um todo reconhecível e imediatamente dado, considera que a ele corresponderia uma ciência específica, sui-generis. Entretanto, os praticantes britânicos de uma Antropologia Social tinham sérias dúvidas a este respeito. Radcliffe-Brown (1958) dizia que uma ciência da cultura é impossível de existir porque a esfera cultural encontra-se imersa na sociedade. Eu diria que a tentação culturalista é retirá-la do contexto mais amplo, ignorando as contradiçóes reais da história. A esfera cultural é, na verdade, um cruzamento de intençôes diversas: econômica, política, sociais. Nela, não se incrusta apenas o simbólico: as representaçôes, os interesses, os conflitos, as determinaçóes históricas, os grupos em disputa são parte de sua existência. Logo, torna-se difícil a considerarmos como uma entidade singular, porque sua vida não é autônoma. Certamente, é na esfera cultural que os símbolos são gestados e preenchidos de sentido; mas, eles se transformam com o peso da história. As mudanças concretas incidem nesta floresta de significados, desviando-os de seu conteúdo original. Contudo, não se deve esquecer o debate sobre a problemática cultural ampara-se, ainda, em uma tradiçâo intelectual que o antecede. Cultura popular, cultura de massa, cultura nacional e cultura elitista são maneiras de denominar questóes que se transformam, mas que pertencem a uma herança que se impóe a nós. Cada um desses termos é carregado de significados distintos, projetando no presente a sombra de sua existência. O terreno da reflexão e do debate em curso vem, dessa forma, marcado pelo jogo de continuidade e ruptura que incide em sua compreensão. 


\section{Referências}

ADORNO, T. A indústria cultural. In: COHN, G. (Ed.): Comunicação e Indústria

Cultural. São Paulo: Editora Nacional, 1975. p. 28 ADORNO; HORKHEIMER. O iluminismo como mistificaçáo das massas.

AGULHON, M. Les Métamorphoses de Marianne: l'imagerie et la symbolique républicaines de 1914 à nos jours. Paris: Flammarion, 2001.

AMERICAN ANTHROPOLOGICAL ASSOCIATION. Statement on Human Rights. American Anthropologist, v. 49, n. 4, p. 539-543, 1947.

BELTRÁN, L. R.; CARDONA, E. Comunicación Dominada: Estados Unidos en los medios de América Latina. Mexico: Nueva Imagen, 1980.

BOURDIEU, P. Esquisse d'une Théorie de la Pratique. Genève: Droz, 1972.

ARNOLD, M. Culture and Anarchy. Cambridge: Cambridge University Press, 1981.

BARTHES, R. Le triomphe et la rupture de l'écriture bourgeoise. In: Le Degré Zéro de l'Écriture. Paris: Ghontier, 1964.

BAUDRILLARD, J. La Société de Consommation. Paris: Denoel, 1970.

BELL, D. The Coming of Post-Industrial Society. New York: Basic Books, 1973.

BENEDICT, R. The Crysanthemum and the Sword. London: Routledge \& Kegan Paul, 1967.

BENJAMIN, Walter. Paris capitale du XIX siècle. In: Parigi Capitale del XIX Secolo. Torino: Einauldi, 1986. p. 31 - Paris, capital do século XIX. In: Passagens. BH: UFMG - SP: Imprensa Oficial do Estado de São Paulo, 2006.

BOBBIO, N. Stato, Governo, Società. Torino: Einaldi, 1985.

BORELLI, S.; LANZDRINI, F. (Ed.). Cultural Heritage, Cultural Rights, Cultural Diversity. Leiden: Martinus Nijhoff Publications, 2012.

BOURDIEU, P. Ce Que Parler Veut Dire. Paris: Fayard, 1982.

As Regras da Arte. São Paulo: Companhia das Letras, 1992.

CASTRO, C. Evolucionismo Cultural. Rio de Janeiro: Zahar, 2005.

CIPOLLA, C. Canhóes e Velas na Primeira Fase da Expansão Européia: 1400-1700. Lisboa: Gradiva, 1989. 
COLlingWOOD, R. G. The Principle of Art. Oxford: Oxford: University Press, 1958.

COOLEY, R.; COOLEY, C. Introductory Sociology. New York: Charles Schribner’s Son, 1933.

CORBISIER, R. Formação e Problemas da Cultura Brasileira. Rio de Janeiro: ISEB, 1959.

DE SWAAN, A. Words of the World. Cambridge: Polity Press, 2001.

EISENSTAD, N. Múltiplas Modernidades. Belo Horizonte: Livros Horizonte, 2007.

ELIAS, N. O Processo Civilizador. Rio de Janeiro: Zahar, 1990.

FANON, F. Sociologie d'une Révolution. Paris: Maspero, 1959.

Les Damnés de la Terre. Paris: Maspero, 1961.

FARIAS, E. Ócio e Negócio: festas populares e entretenimento-turismo no Brasil. Curitiba: Ed. Appris, 2011.

FERRO, M. História das Colonizaçóes. São Paulo: Companhia das Letras, 1999.

FOUCAULT, M. Les mots et les choses. Une archéologie des sciences humaines. Paris: Gallimard, 1966.

FRIEDMAN, B. The Feminine Mystique. New York: W. W. Norton Co., 1963.

GELLNER, E. Nations and Nationalism. Oxford: Oxford Blackwell, 1983.

GILLE, B. Histoire des Techniques. Paris: Gallimard, 1978.

GOODY, J. The East in The West. Cambridge: Cambridge University Press, 1996.

HABERMAS, J. L'Espace Public. Paris: Payot, 1978.

HALL, S. A Identidade Cultural na Pós-Modernidade. Rio de Janeiro: DP\&A Editora, 1992.

HARVEY, D. The Condition of Postmodernity. Cambridge: Basil Blackwell, 1990

HERDER, J. Une Autre Philosophie de l'Histoire. Paris: Aubier, 1964.

HOBSBAWM, E. Era dos Impérios: 1875-1914. Rio de Janeiro: Paz e Terra, 1988.

HOBSON, J. A. Imperialism: a study. London: James Nisbet \& Co, 1902.

HONNETH, A. La Lutte pour la Reconnaissance. Paris: Les Éditions du Cerf, 2010.

HORKHEIMER, M. Art and Mass Culture. Studies in Philosophy and Social Sciences, v. 9, n. 2, p. 290-304, 1941. 
IANNI, O. O Labirinto Latino-Americano. Petrópolis: Vozes, 1993.

JACOBS, N. Culture for the millions?: mass media in modern society. Van Nostrand, 1961.

JENKS, C. The Language of Post-modern Architecture. London: Academy Editions, 1981.

KAMENETSKY, C. The german folclore revival in eitheenth century: Herder's theory of naturpoesie. Journal of Popular Culture, n. 4, spring 1973.

KROEBER, A. L. The Nature of Culture. Chicago: University of Chicago Press, 1952.

The Theft of the History. Cambridge: Cambridge University Press, 2006.

C.; KLUCKHON, Culture: a critical review of concepts and definitions. Cambridge:

The Museum, 1952.

LANDES, D. Revolution in Time: clocks and the making of the modern world. Cambridge: The Belknap Press, 1983.

LARRAÍN, J. Modernidad Razon e Identidad en America Latina. Santiago de Chile: Ed. Andrès Bello, 1996.

LASH, S.; URRY, J. The End of Organized Capitalism. Madison: University of Wisconsin Press, 1987.

LE BON, G. Psicologia das Multidóes. Rio de Janeiro: Delraux, 1980.

LEPENIES, W. Seduction for Culture in German History. Princeton: Princeton University Press, 2006.

LYONS, G. M.; MAYALL, J. (Ed.). International Human Rights in the $21^{\text {st }}$ Century. Lanham: Rowman \& Littlefield Publishers Ind., 2003.

LYOTARD, J. F. O Pós-moderno. Rio de Janeiro: José Olympio, 1986.

MATTELARD, A. Multinationales et Systèmes de Communication. Paris: Anthropos, 1976. .; DORFMAN, A. Para Leer el Pato Donald. Valparaiso: Ediciones Univesitarias, 1973.

MCLUHAN, M. Understanding Media: the extensions of man. New York: McGraw-Hill Book Co., 1965.

MOULIN, R. Le Marché de l'Art: mondialisation et nouvelles technologies. Paris: Flammarion, 2000.

MUNFORD, L. Técnica y Civilización. Madrid: Alianza Editorial, 1987.

NICOLAU, M. O Discurso da Diversidade e a World Music. São Paulo: Annablume, 2014. 
ORTIZ, Renato. Um Outro Território. São Paulo: Olho d’Água, 1996.

O Próximo e o Distante: Japão e modernidade-mundo. São Paulo: Brasiliense, 2000.

. Universalismo e Diversidade: contradiçôes da modernidade-mundo. São Paulo: Boitempo, 2015.

RADCLIFFE-BROWN, A. R. Method in Social Anthropology. Chicago: The University of Chicago Press, 1958.

RENAN, E. Quest-ce qu'une Nation. Paris: Editions Pocket, 1992.

RIFKIN, J. A Era do Acesso. São Paulo: Makron Books, 2001.

ROCHA, G. Estética da Fome. Arte em Revista, São Paulo, v. 1, n. 1, p. 15-17, 1979.

ROSEMBERG, B.; WHITE, D. M. Mass Culture: the popular arts in America. New York: The Free Press, 1957.

ROUILLÉ, A. (Ed.). La Photographie en France: textes et controverses. Paris: Macula, 1989.

SACRISTE, F. S. Germaine Tillion, Jacques Berque, Jean Servier et Pierre Bourdieu: des ethnologues dans la guerre d'indépendance algérienne. Paris: L'Harmattan, 2001.

SARTRE, J. P. Qu'est-ce que la Littérature?. Paris: Gallimard, 1948.

SAUSSURE, F. de. Escritos de Linguística Geral. Campinas: Cultrix, 2002.

SCHAFT, A. A Sociedade Informática. São Paulo: Unesp; Brasiliense, 1991.

SHILS, E. Mass Society and Its Culture. In: JACOBS, N. Culture for the millions?: mass media in modern society. Van Nostrand, 1961.

STAMATOPOLOU, E. Cultural Righs in the Internaional Law Article 27 of the Universal Declaration of Human Rights and Beyond. Leiden: Martinus Nijhoo Publ., 2007.

STEIGER, J. et al. The Classical Hollywood Film. New York: Columbia University Press, 1985.

TARDE, G. L’Opinion et la Foule. Paris: PUF, 1989.

TAYLOR, C. Multiculturalisme: différence et démocratie. Paris: Aubier, 1994.

TAYLOR, 2010.

THOMPSON, J. B. Merchants of Culture. London: Penguin Book, 2012.

TYLOR, E. B. Primitive Culture. Cambridge: Cambridge University Press, 2010. 
TUNSTALL, J. The Media are American. New York: Columbia University Press, 1977.

UNESCO. Declaração Universal sobre a Diversidade. Paris: UNESCO, 2001.

URRY, J. Consuming Places. London: Routledge, 1995.

VARIS, T.; NORDENSTRENG, K. Television: a One-Way-Street?. Reports and Papers on Mass Communication, n. 70. Paris: UNESCO, 1974.

VINCENT, J. Anthropology and Politics: visions, traditions, and trends. Tucson: The University of Arizona Press, 1990.

WEBER, A. História Sociológica da Cultura. São Paulo: Mestre Jou, 1970.

Peasants into Frenchmen. Palo Alto: Stanford University Press, 1976.

WEBER, W. La Gran Transformación en el Gusto Musical. México: Fondo de Cultura Económica, 2011.

WILLIAMS, R. Culture \& Society. New York: Columbia University Press, 1983.

ZEA, L. El Pensamiento Latinoamericano. Ciudad de Mexico: Ed. Pomarca, 1965.

\section{Culture and Contemporary World}

\section{Abstract}

In view of contemporary relevance obtained by culture and its derivatives, by combining history of concepts with ethnography of ideas, an overview of the semantic changes in the notion of culture is drawn. However, in doing so, it is not the purpose to make an exhaustive inventory of this wide semantic framework. With the support of the categories of "constellation of meanings" and of "geological strata", three distinct layers that ad up to the understanding of the idea of culture are differentiated and analyzed: "culto, cultivado, arte", "culture as a whole" (nation and anthropological studies) and "mass culture". Although bearing in mind the existing gap between the three constellations, regarding the novelty that they engender in the problem of culture, they are not taken as isolated from each other, it is chosen to observe how they intertwine and, in particular, how they become mutual references.

Keywords: Culture. Constellation of meanings. Geological strata. Contemporary world. 